Aleksandra Filipović,

UDK: 904:726.8"653"(560-13)

Ricercatore libero presso il Dipartimento di

ID: 195903500

Storia, disegno e restauro di architettura,

Universita di Roma

Original research article

aleksandra@z80.it

Received: August 17, 2011

Accepted: September 05, 2011

\title{
UNA NECROPOLI BIZANTINA NEL GOLFO DI BELCEĞIZ: LICIA MERIDIONALE*
}

\begin{abstract}
Nel golfo chiamato Belceğiz, diverse località archeologiche databili al VI secolo, sono collocate su due isole (Gemile e Karacaören) e la terraferma propinqua (Beştaş, Gemile Köyü e Yarım adası), creando insieme una unità urbanistica ben strutturata. Le vaste necropoli sono collocate soprattutto su due isole, mentre lungo le coste le tombe preservate sono poche e isolate. Sull'isola più grande, Gemile, che è anche il cosiddetto centro urbano, diverse necropoli sono situate nelle aree isolate rispetto alle zone residenziali, con poche tombe distaccate ma integrate nel tessuto urbano. Nell'isola più piccola, Karacä̈ren, la necropoli occupa maggior paate del territorio, e probabilmente divento un luogo di pellegrinaggio locale. Questo contributo tratterà l'analisi delle necropoli con l'architettura di alcune tombe selezionate per le loro forme specifiche e alcune invece per le forme tipiche, le considerazioni finali architettoniche, le tecniche di progettazione, metodi di costruzione e materiali, affreschi e intonaci di finitura, datazione e la conclusione.
\end{abstract}

\section{PAROLE CHIAVE: NECROPOLI, TOMBA, CHAMOSORION, CUPOLA, VOLTA, MURATURA, CALCARE, LATERIZIO, COCCIOPESTO, STILATURE.}

A sud dell'odierna città di Fethiye, l'antica Telmessos di Licia, si estende un golfo, di nome Belceğiz (fig. 1). In un paesaggio tipicamente mediterraneo, due isole, quella di Gemile e di Karacaören si stagliano nel mare, difficilmente distinguibili da lontano per il viaggiatore che arriva da sud. Il golfo con i relativi insediamenti sono stati campo di lavoro archeologico dagli inizi degli scorsi anni 90 soprattutto ad opera di una équipe giapponese che dopo un iniziale survey, ha scavato parzialmente una chiesa (Chiesa III) sul sommitale di Gemile ${ }^{1}$. Dal 1999 al 2003 sono sta-

1 Per queste due isole e gli insediamenti a terra, si veda: Tsuji 1995, Asano 2010, Id. 2002 (con i primi risultati di

* Desidero ringraziare il prof. Vincenzo Ruggieri, che mi ha gentilmente invitato a fare parte delléquipe archeologica del Pontificio Istituto Orientale nel periodo dal 2006 al 2010. Un ringraziamento a parte va ai colleghi sul campo che hanno lavorato con me in questi anni di ricerca: Matteo Turillo, Domenico Mignosa, Morgan De Rodi e Giuseppe Sbaraini. Per le chiese su Gemile si useranno per convenzione le sigle degli archeologi Giapponesi; alle tombe sono state applicate delle sigle per rendere il testo più scorrevole. Per ulteriori informazioni sulle tecniche murarie e altre questioni architettoniche del medesimo argomento si veda: Filipović 2012a, 149-177 e Id. 2012b 439-466. 


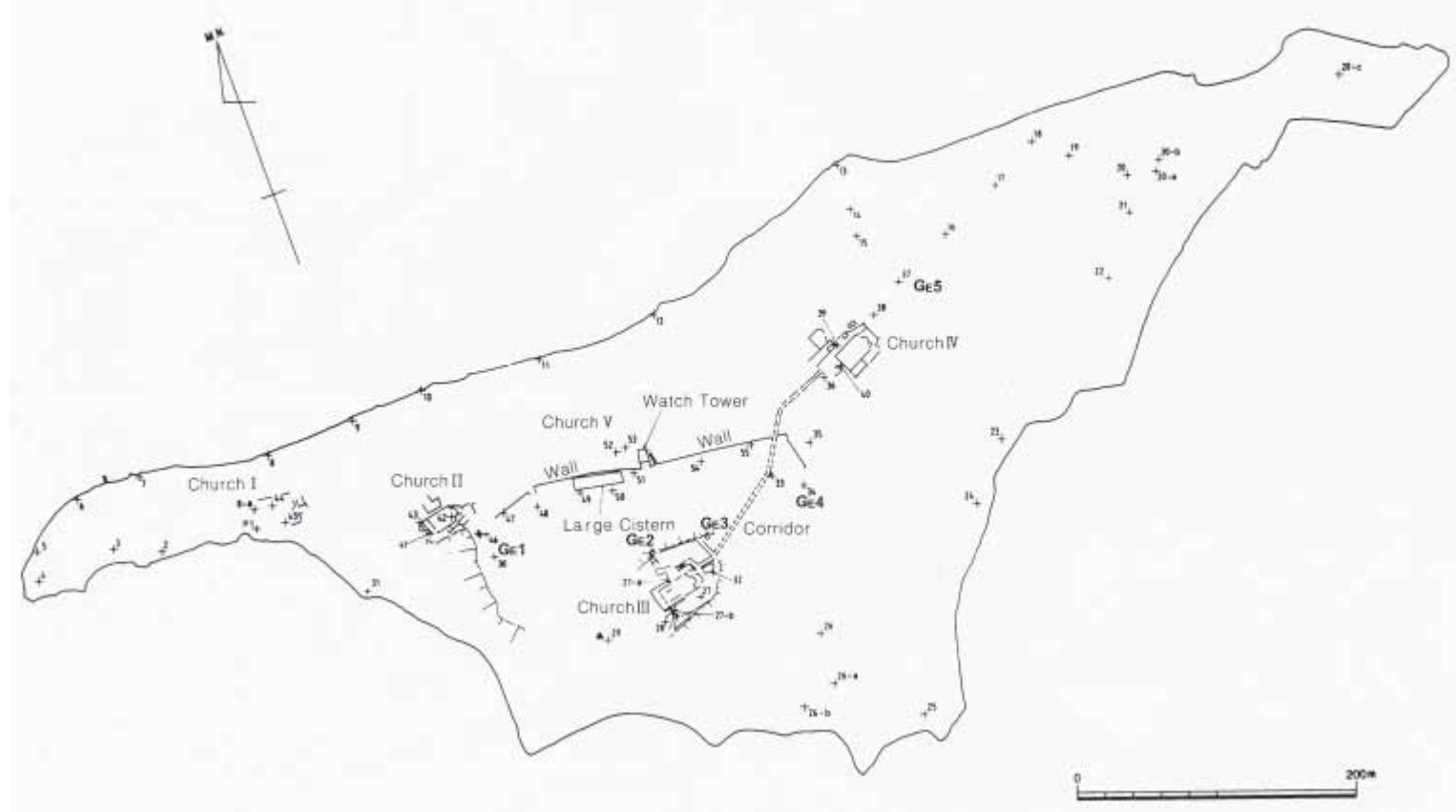

Fig. 2. Isola di Gemile con indicazione delle tombe. Da Tsuji 1995 rielaborata.

ti intrapresi lavori di scavo, concentrati su alcuni siti posti sulla terraferma, condotti dalla direzione del museo archeologico di Fethiye e coadiuvati da Shigebumi Tsuji². Le due isole facevano parte una volta di un insieme più ampio: geograficamente oggi si parte dalla baia di Ölüdeniz a sud, andando poi verso ovest toccando Beştaş, Gemile Köyü, Gemile adası, Karacaören adası, finendo con Yarım adasi. In questo contesto urbano, solo due isole conservano un insieme architettonico sepolcrale che possa considerarsi una unità ben strutturata. Giacché si tenterà di leggere l'impegno architettonico versato su queste unità-necropoli, la presente ricerca terrà, quindi, in considerazione l'isola grande di Gemile e quella più piccola di Karacaören.

In altra sede è stato trattato questo territorio considerandolo come un "insieme urbanistico

scavo sulla Church III); Foss 1994, 6-9; Hellenkemper und Hild 2004: 681-683 s.v Perdikonêsi e 599-601 s.v. Karacaören Limanı und Ada; per la tecnica ed affreschi di alcune tombe su Karacaören, cf Ruggieri e Turillo 2007, 123-130.

2 Tsuji 2001, 3-26; Malkoç and Tsuji 2005, 1-24. ed architettonico", sottolineando soprattutto l'aspetto topografico di un centro urbano, l'isola di Gemile, con diversi insediamenti extraurbani sulla terraferma aventi differenti mansioni ${ }^{3}$. Il culmine dello sviluppo raggiunto da questo complesso insediativo è stato certamente tutto l'arco del VI secolo, quando ancora il traffico marittimo sulle coste licie produceva oltre gli scambi culturali una ricchezza economica che giustificava in gran parte anche l'architettura funeraria. In seguito, attorno alla metà del VII secolo, v'è stata la flessione urbana e sociale dovuta alle razzie arabe protrattesi per un lungo periodo prima di una debole ripresa in epoca medievale. Quest'ultima fase, riscontrabile nelle due isole delle quali si parlerà, resta limitata e si prolunga probabilmente fino al pieno XIII secolo. L'intento di queste pagine non prevede l'analisi architettonica di tutta questa sezione del golfo, quanto piuttosto di valutare il significato della molteplice e buona produzione di archite-

3 Ruggieri 2012, 883-902. Lo Stesso ha trattato questa geografia in: Ruggieri 1998, 140-147 e in: Ruggieri 2009, 81-108 prendendo in considerazione anche del materiale marmoreo appartenente all'isola di Gemile. 


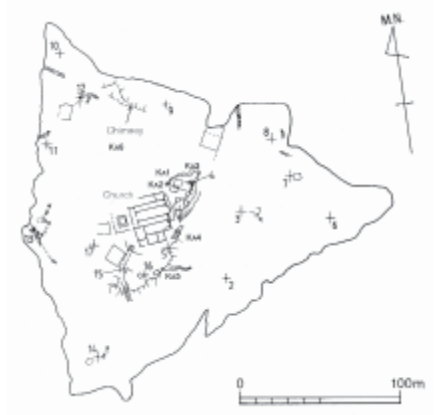

Fig. 3. Isola di Karacaören con indicazione delle tombe. Da Tsuji 1995 rielaborata.

ttura sepolcrale concentrata sulle due isole. Si è voluto, inoltre, evitare un'analisi degli affreschi presenti sporadicamente all'interno di qualche tomba: questo argomento, affrontato in passato da qualche studioso, esula da quanto è lo scopo di questo lavoro, lasciando l'intera lettura di qualche ciclo agli storici dell'affresco. Dato il considerevole numero di tombe si terrà conto soprattutto di quelle più singolari e di altre che rappresentano gli esempi meglio riusciti architettonicamente all'interno di una comune tipologia. Quando e dove sarà necessario si farà ricorso a similitudini tecnico-costruttive riscontrabili in questo territorio o in quello più vicino. Benché vi siano state pubblicazioni da parte dell'équipe giapponese, le caratteristiche tipicamente architettoniche di questa eredità archeologica cristiana non sono state affrontate.

\section{ACCENNI SULL'URBANISTICA ED ARCHITETTURA DI GEMILE E KARACAÖREN.}

L'isola di Gemile è lunga circa $1000 \mathrm{~m}$ e larga circa $350 \mathrm{~m}$ nella parte centrale (fig. 2). Si tratta di una collina calcarea, ripida sui versanti nord e sud ed estesa in lunghezza secondo l'asse est-ovest. La lunghezza del versante nord crea un riparato corridoio di mare dalla terraferma, largo circa $300 \mathrm{~m}$, che ospita lungo la costa tutte le maggiori attività commerciali della città. Anche se posta in un'area altamente sismica, oggi su Gemile si possono ancora distinguere i magazzini a mare e i moli di attracco stesi lungo l'asse estovest. A distanza irregolare salgono dalla costa scalinate verso la criniera della collina tagliando gli insediamenti abitativi. Questa zona non è stata propriamente rilevata dall'equipé a causa della ripida caduta del versante. Perciò viene da supporre, considerando la concentrazione di case e strutture adiacenti, che si sia intervenuto con terrazzamenti posti sistematicamente a diverse altezze ${ }^{4}$. Sul crinale della collina, partendo dalla quota più bassa ad ovest, corre quanto si può ritenere l'asse viario principale che collega le quattro basiliche presenti sull'isola ${ }^{5}$. Questa strada sale a serpentine quando i livelli sono considerevoli e diventa più lineare, come presso la Chiesa II dove affronta un camminamento pianeggiante. Al raggiungimento della Chiesa III, posta sul sommitale della collina, la strada scende di quota per arrivare alla Chiesa IV e diventa un elegante passaggio voltato (corridoio voltato), aperto con archi su ambo i lati. Gli insediamenti abitativi sono legati a nord soprattutto con la Chiesa I e Chiesa II, restando distaccati ed a quota più bassa rispetto alla Chiesa III e IV. Sembra che la città non possieda monumenti ludici ed è da dedurre che tutta la vita pubblica su Gemile si svolgesse in collegamento alle basiliche. Per l'approvvigionamento idrico sono state costruite numerose cisterne, tutte probabilmente private. Una, invece, era certamente pubblica dato che aveva dimensioni considerevoli (32.85 per $5.30 \mathrm{~m}$ ), costruita con molta perizia tecnica versata soprattutto per contenere l'invaso dalla caduta di quota a nord. Un'altra grande struttura rettangolare con

\footnotetext{
4 In effetti un muro possente di contenimento corre ad un'altezza di ca. $60 \mathrm{~m}$ s.l.m. e si ritiene che il muro assume una funzione di tenuta del terreno sovrastante a difesa di una sezione parziale del lato nord, andando poi ad intersecare il corridoio voltato fra la Chiesa III e la Chiesa IV. 5 L'equipé giapponese ha rilevato la presenza di un'altra chiesa, le cui tracce non sono state accertate da parte dell'autore. La presenza del forte crollo nella zona centrale del versante nord rende difficile la lettura delle costruzioni di questa area.
} 


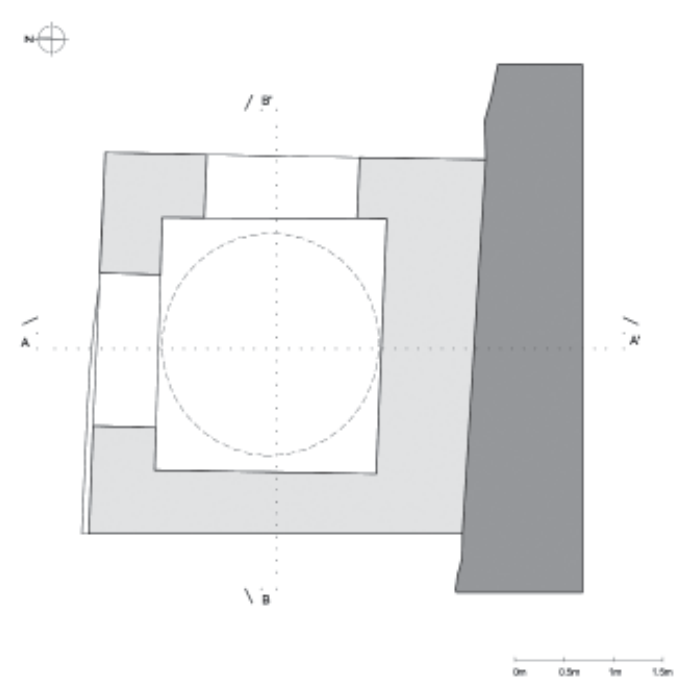

Fig. 4. Ge1, pianta.

volta a botte e muri di $90 \mathrm{~cm}$ paralleli alle generatrici della volta giace all'estremo limite orientale dell'isola, probabilmente un grande deposito per cereali. Il sistema fognario è rintracciabile a sud della Chiesa I ove sovrasta i magazzini scendendo a mare all'aperto e a nord, ove la condotta coperta si apre a mare in diverse sezioni fra gli impianti commerciali.

L'isola di Karacaören è di gran lunga più piccola e dista circa un miglio a sud-ovest di Gemile (fig. 3). L'impianto che occupa la cima dell'isola è costituito da una grande basilica a tre navate, con un annesso a sud usato anche in epoca medievale. Le tombe si spargono d'attorno senza un manifesto piano di insediamento. Ad ovest della basilica si aprono delle grandi strutture a due piani, forse per abitazioni. Approdi e accessi scavati nella roccia a nord e a sud-ovest salgono verso il complesso ecclesiastico ed alle tombe. Alla Chiesa I su Gemile e a quella su Karacaören si lega un impianto battesimale rispettivamente a sud-est e sud-ovest. La Chiesa IV e quella su Karacaören hanno un annesso absidato a sud ornato da un fregio ad archi ciechi su lato nord; la Chiesa I e II, da parte loro, e la basilica su Karacaören mostrano un anello quasi circolare che corre dietro l'abside centrale usato probabilmente come skevophylakion.

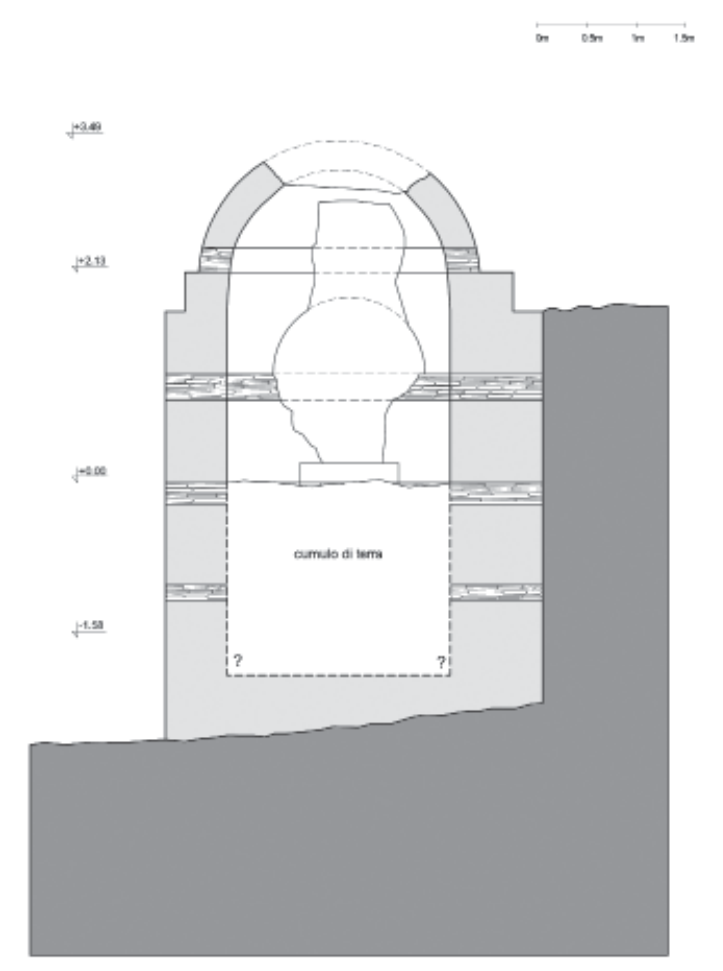

Fig. 5. Ge1, sezione AA'.

\section{TOMBE A GEMILE}

Lo studio ancora ipotetico sull'estensione urbana della città di Gemile non ha toccato la funzione delle necropoli e la loro connessione con il centro urbano. Inoltre, non si è avuta una disamina sociale dei defunti in relazione alla tipologia e fabbrica delle tombe stesse considerando anche che non sono state trovate epigrafi che testimoniano committenti ${ }^{6}$. All'interno di questo territorio, v'è una mancanza di fonti che elargisca note di topografia cristiana, a fortiori di necropoli cristiana.

Nell'isola di Gemile le necropoli si trovano in diverse aree, con alcune tombe integrate nel tessuto urbano ${ }^{7}$. La prima necropoli è collocata

6 Per questo caso si veda dopo. Queste domande metodologiche sono state affrontate da Çevik 2006, 177178. In occasione di questo simposio s'è scritto molto sulle necropoli e tipologie tombali licie, ma in epoca classica. Si attende la pubblicazione sulla facies christiana di Xanthos per avere possibili riferimenti comparativi sul nostro soggetto.

7 Per fermarsi al territorio più vicino, casi di sepoltura sono stati analizzati da Ruggieri 1991, 194 (grande tomba 


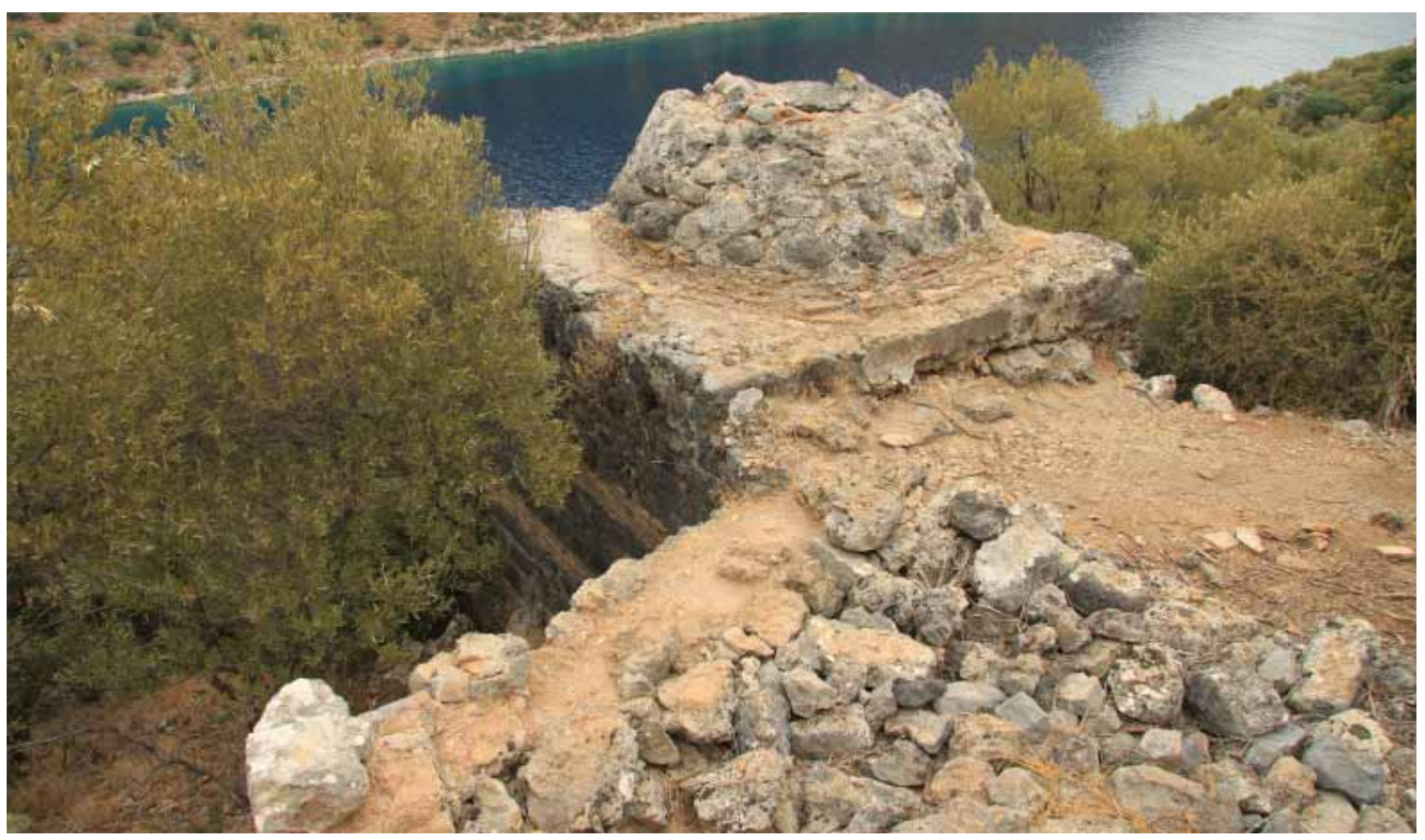

Foto 1. Ge2, tomba a cupola 1. Prospetto generale da sud-ovest.

lungo il percorso tra la Chiesa II e la Chiesa III, in un'area distante dalla zona abitativa. È un gruppo di tombe di varia tipologia e importanza, poste quasi sul pendio scosceso dal quale si vede la terraferma, l'isola di Karacaören e la baia di Gemile Köyü. La seconda necropoli si stende a sud rispetto al corridoio voltato. Questa sembra addossata alla seconda fase costruttiva del corridoio voltato dove questo cambia direzione e inizia appunto con una tomba di notevoli dimensioni, a camera doppia, che entra in una arcata (foto 8$)^{8}$. La terza necropoli, chiamata anche necropoli orientale, è collocata ad est rispetto alla Chiesa IV; essa è distaccata dalle aree abitative pur se non lontana dalla zona residenziale più ricca dell'isola. Diverse tombe isolate non appartengono ad un gruppo funerario e tra di esse alcune sono collocate nei pressi di chiese e sembra che fossero di notevole importanza. Non è solo la posizione strategica

a camera relativa ad una ricca villa con terme); Id. 1999, 298-305 (villaggio con necropoli e tombe sparse); Ruggieri - Zaffanella 2000, 79-82 (tombe a camera legate ad una chiesa).

8 Per una corretta comprensione del contesto architettonico si ritiene importante specificare che il corridoio voltato presenta probabilmente tre fasi di costruzione. che le distingue, in alcuni casi è loro architettura particolare all'interno di questo contesto urbano.

\section{TOMBE A CUPOLA}

Nei pressi della Chiesa III, sui margini esterni del terrazzamento nord, vi sono due tombe di simile tipologia, di pianta quadrangolare e a forma di parallelepipedo cupolato. Una è posta ad ovest del terrazzamento, addossata ad una struttura che chiude l'accesso al terrazzo (foto 1), l'altra è dalla parte l'opposta ad est, lungo il percorso che conduce verso il corridoio voltato (foto 3 ).

\section{Tomba a cupola 1 (Ge1, fig. 4)}

La prima tomba ha il vano che misura 2.30 per $2.55 \mathrm{~m}$, con i muri spessi sui $60 \mathrm{~cm}$, dove quello addossato al terrazzo arriva ai $95 \mathrm{~cm}$. L'edificio è di notevole altezza e dall'esterno raggiunge 6.05 m compresa la cupola (fig. 5). All'interno esso è organizzato su due livelli: il superiore presenta un 


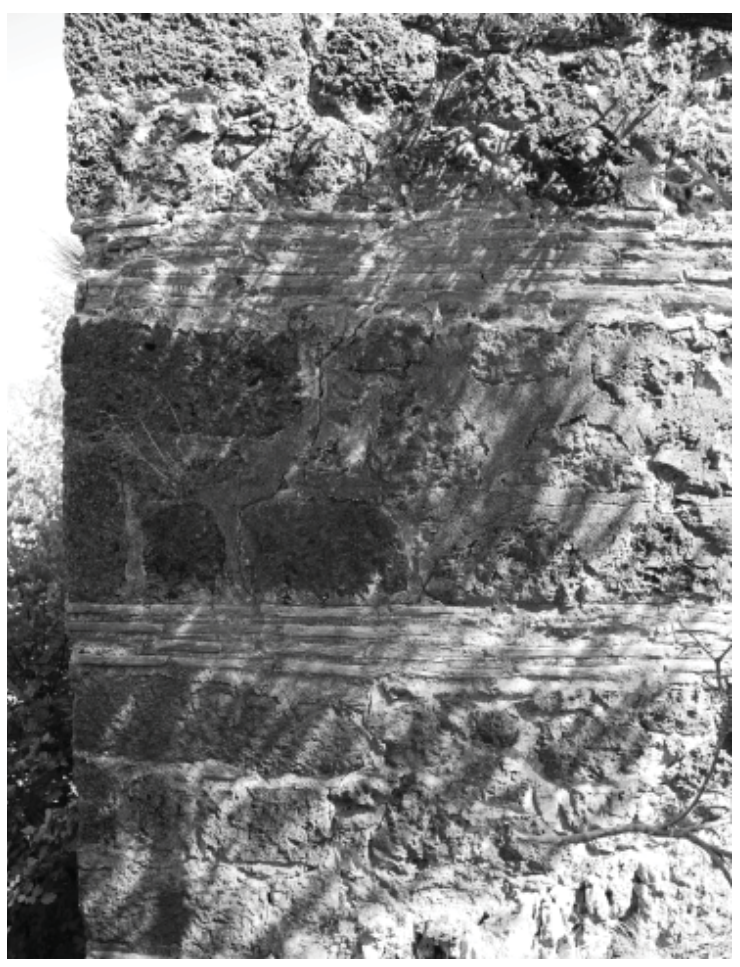

Foto 2. Ge2, tomba a cupola 1. Muro ovest, dettaglio della tecnica muraria.

ammasso di crollo che rende difficile capire l'esatta articolazione del suo spazio, mentre l'inferiore contiene la sepoltura e nulla si può dire sulla interrelazione tra essi. L'ingresso della camera funeraria è posto ad est ad un livello inferiore dal calpestio del terrazzamento dalla classica forma rettangolare. I resti ancora leggibili di probabili gradini in muratura posti all'angolo nord-est fanno pensare che l'accesso alla camera funeraria avvenisse in questo modo. Nulla può dirsi su come fosse organizzata la camera inferiore considerando che anche in questo vano il crollo è completo'. L'interno della cupola è a vista e il vano superiore è illuminato da due aperture arcuate e ben rifinite, aperte sui muri nord e est.

La struttura tombale mostra sul versante nord un rafforzo murario; il lato ovest, invece, presenta parzialmente roccia viva lasciata come fondazione. La sua muratura appartiene ad una

9 In questo caso sono le fistule poste sul muro esterno nord del piano inferiore a dare la posizione del calpestio della camera funeraria, funzionali per lo scolo.

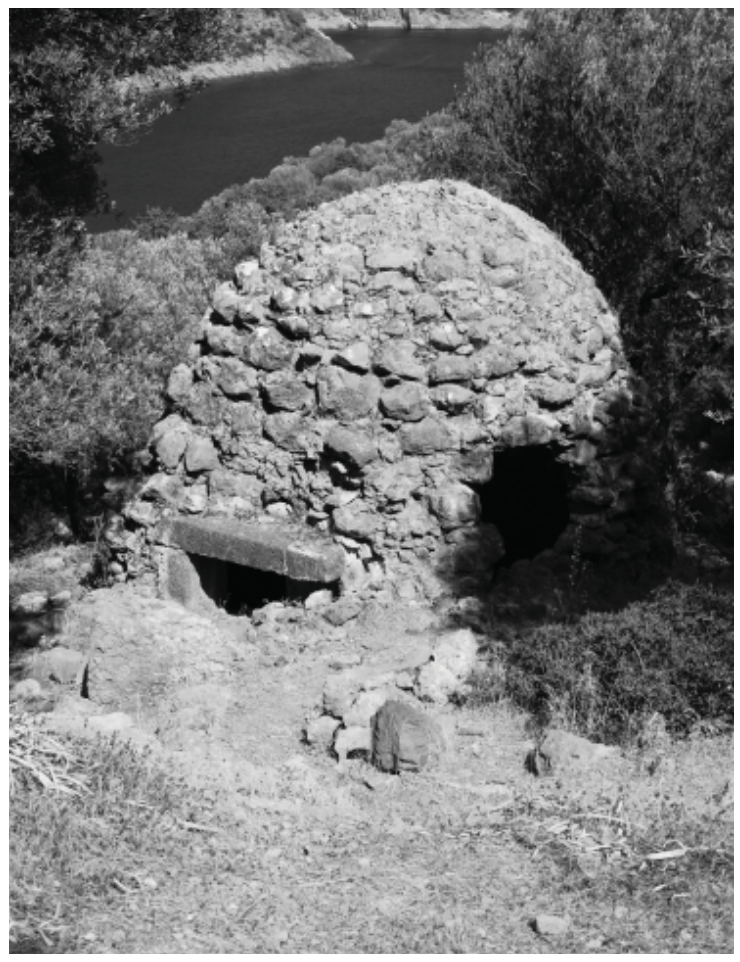

Foto 3. Ge3, tomba a cupola 2. Prospetto generale da sud-ovest.

versione tecnica dell' opus mixtum e opus quadratum composta da filari di conci alternati a fasce orizzontali di laterizio ${ }^{10}$. La fascia con filari di conci ha il nucleo murario a sacco, mentre sembra che la fascia in laterizio copra tutto lo spessore del muro. L'altezza delle tre fasce di laterizio cambia andando dal basso verso alto: la prima fascia - sopra il basamento - contiene tre file di laterizio, la seconda ne ha quattro, e l'ultima ne ha cinque ${ }^{11}$.

10 L'impiego del mattone nella realizzazione di questo modulo non è usuale in Licia. Si rinviene nella calotta absidale della chiesa sulla spiaggia a Kekova (Kakaba; Hellenkemper und Hild 2004, 582; foto 153); in un impiego, forse più tardivo, nell'estradosso poligonale dell'abside della chiesa di S. Nicola a Myra (fase altomedievale); in vari edifici civili di Olympos e, sempre in questa città, nelle coperture a cupola delle terme coi mosaici; nelle terme di Domuz Adas1: Ruggieri 1991, 189-191. Nell'edificio termale di Olympos, non ancora propriamente pubblicato, v'è un'altra caratteristica relativa al laterizio. Nel modulo alternato con mattoni e conci nel fronte degli archi, il laterizio viene puntellato con gocce di affresco bianco; a Karacaören, sull'arco cieco sovrastante l'ingresso nel battistero dall'annesso sud della chiesa, si sono dipinti i mattoni con gli stessi punti bianchi di affresco.

11 Ciò significa che sono stati usati mattoni differenti, 


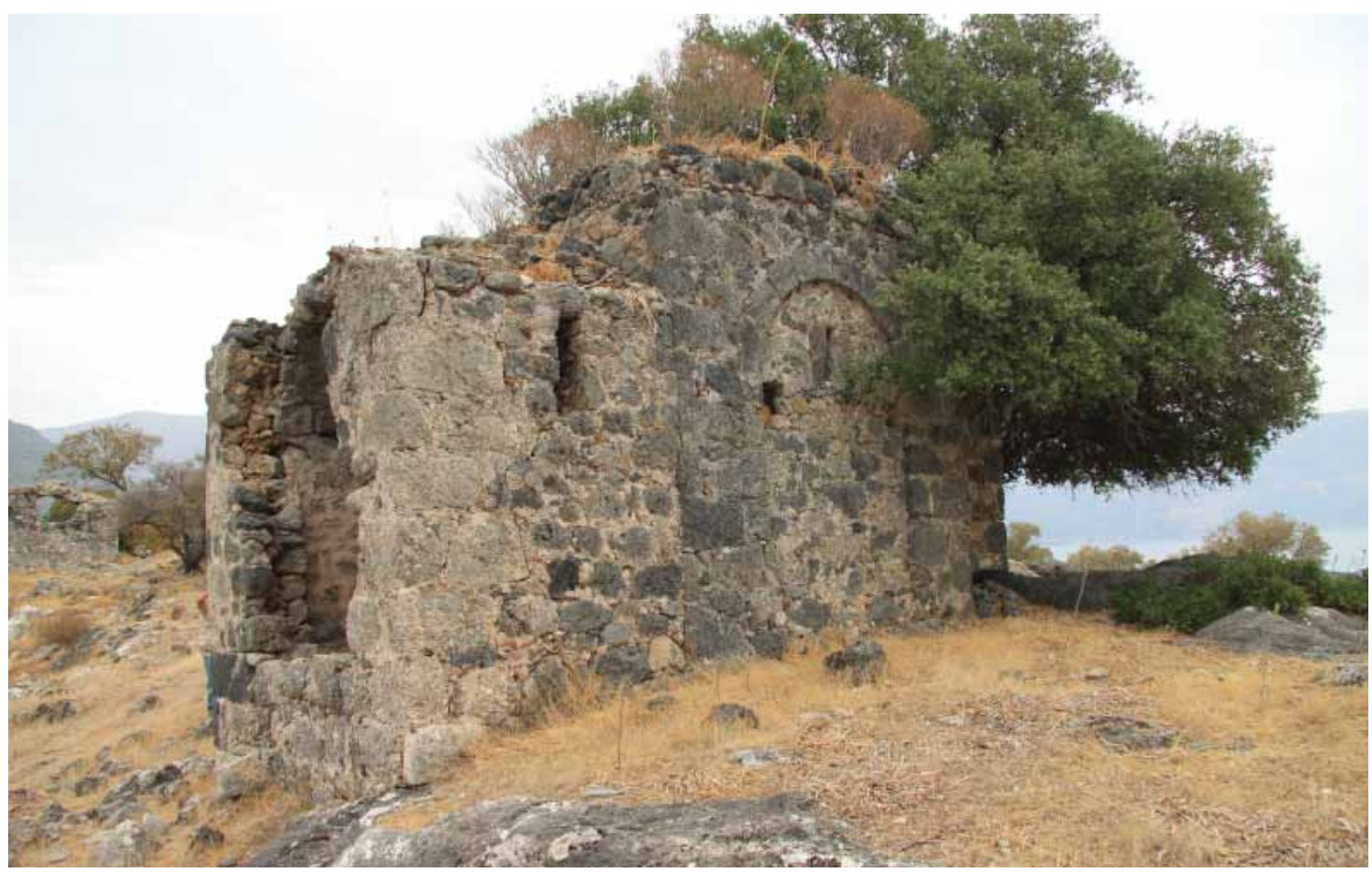

Foto 4. Ge5, tomba a croce. Prospetto nord-ovest.

L'altezza della fascia in pietra resta sempre uguale.

Per raccordare una base quadrata, i pennacchi partono dalla stessa altezza dell'imposta delle finestre arcuate, cioè dalla fine dell'ultimo strato di laterizio. I muri sui versanti nord e sud mantengono il piombo fino alle curvature dei pennacchi; non cosi per gli altri due versanti, dove il muro presenta la dovuta curvatura per raggiungere la base quadrata. Anche per la calotta si riscontra il modulo murario affidato al laterizio posto su cinque file. La sezione presenta una muratura a sacco, con materiale affogato in molta malta, e il facciavista mostra la posa radiale delle scaglie calcaree, come sarà il caso per le altre cupole di quest'isola. All'interno del vano superiore, sul muro sud si vedono le buche pontaie: due inferiori che poggiano sul modulo centrale di laterizio ed ancora due più in alto sopra il modulo più alto di laterizio. L'interno è tutto coperto con uno strato di intonaco di colore bianco rosato e lisciato quasi

quasi certamente presi altrove. In effetti, se da una parte si constata che v'è molto uso di cocciame, non può dirsi similmente per un regolare uso di mattone nella muratura. perfettamente, la cui buona qualità ha permesso una conservazione quasi completa della stesura. Ad oggi ciò che resta all'interno del vano non conserva sfortunatamente nessuna traccia di affresco.

\section{Tomba a cupola 2, (Ge2)}

La seconda tomba a cupola è collocata presso il corridoio voltato, ad una quota più bassa rispetto al terrazzamento. Anch'essa come la Ge1 presenta una pianta quadrangolare, ma leggermente più grande, con le misure complessive esterne che registrano 3.40 per $3.40 \mathrm{~m}$. I muri perimetrali che partono sopra l'ingresso oggi toccano $30 \mathrm{~cm}$ e sono troppo sottili per una costruzione a cupola. Infatti, le dimensioni ridotte delle murature e il loro aspetto esterno, che sembra non rifinito, fa pensare ad una eventuale rimozione posteriore o più probabilmente ad un crollo del facciavista esterno (foto 3). Nonostante questo effetto scheletrico di muratura, la struttura non mostra nessun segno di cedimento murario e la cupola si è pre- 


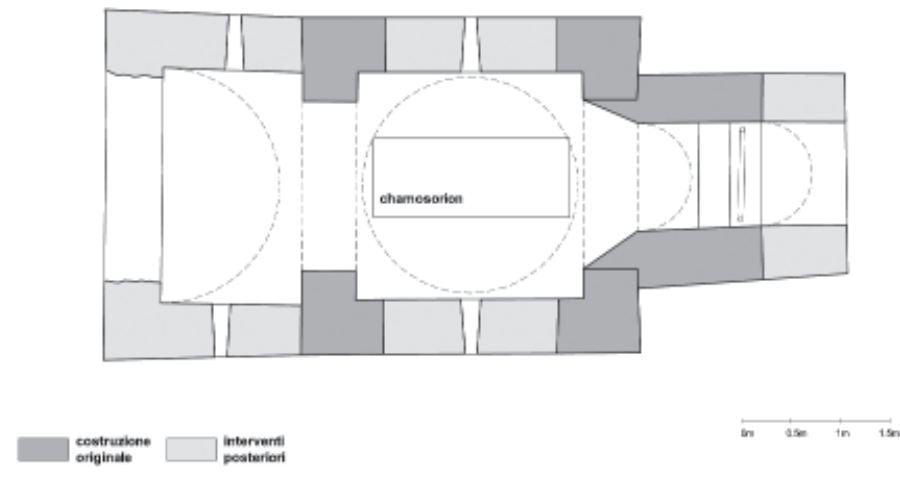

Fig. 6. Ge3, pianta.

servata quasi intatta. La posizione della tomba sotto il terrazzamento ha causato il riempimento del vano interno al punto da impedire qualsiasi ipotesi sul come l'interno fosse strutturato. Da quanto risulta oggi, il calpestio non mostra massi caduti dalla muratura sovrastante, quanto terreno di diporto che scendeva dal terrazzamento. V'è tuttavia da rilevare che davanti all'ingresso, accanto al colmo del crollo, si trovano in posa dei consistenti conci che lasciano pensare ad un ingresso, forse disegnato con aggetti per marcare una forma di distinzione.

La cupola è leggermente a sesto rialzato e si sostiene su quattro pennacchi irregolarmente costruiti. L'apertura al vano sepolcrale si affida ad un possente trilite e la lastra di chiusura, parzialmente conservata. Anche se oggi la tomba è priva del suo aspetto esterno, la carenza del rivestimento resta preziosa nel capire l'articolazione del paramento di questa muratura in cementizio che usava la forza di compressione nella curvatura della cupola ${ }^{12}$.

\section{Tomba a croce (Ge3, fig. 6)}

Al di fuori dei quartieri abitativi, camminando verso la parte est dell'isola, oltre la quarta basilica, nell'area chiamata necropoli orientale, prevalgono le tombe a chamosorion e a camera.

12 A ben vedere, mentre il sacco del paramento esterno - visibile soprattutto in altezza sul lato nord - si affida a pezzame medio, per la volta della cupola si è fatto ricorso a blocchi più grandi, pur se non regolarizzati.
Tuttavia, tra di esse una si distingue per le dimensioni più grandi e per la sua forma particolare. La sua si potrebbe forse definire tipologia a cro$c e$, perché nella sua forma definitiva è un parallelepipedo con una cupola al centro. L'edificio è eretto su una lieve pendenza in posizione perpendicolare alla salita e orientata quasi perfettamente nella direzione nord-sud, e mostra diverse fasi costruttive non facilmente databili (foto 4).

Alla prima fase costruttiva appartiene il corpo di pianta perfettamente quadrangolare di $3.45 \mathrm{~m}$ su ogni lato, coperto con la cupola. Questo nucleo ha un unico vano definito da quattro piedritti angolari, aperto su tutti i lati da archi a tutto sesto, con identiche dimensioni, di cui quello sud, più alto, sembra fungere da ingresso. A loro volta, gli archi sono uniti da quattro pennacchi e raccordati dall'esterno da un vero tambour carée. Dato che essi al loro culmine non definiscono una base circolare, viene creata una fascia intermedia di muratura in conci che andando verso l'alto continua a restringersi per arrivare ad una forma circolare per l'imposta della calotta. Dall'esterno, invece, il nucleo della tomba si presenta molto più semplice, come un paralellepipedo su cui è posta una cupola di cui è visibile solo il suo sommitale. All'interno del vano centrale si trova un chamosorion di forma rettangolare scavato nella roccia lungo l'asse d'ingresso (nord-sud). Il nucleo centrale è privo di fondazioni e l'edificio poggia sulla roccia regolarizzata. Le murature del vano centrale mostrano una cura maggiore dedicata al paramento interno, in opus quadratum abbastanza regolare con conci ad angoli arrotondati (foto 5). Tutto il sistema di copertura, inclusi anche $i$ pennacchi, mostra le giunture fra i conci coperti da uno strato di malta, incisi per creare le fasce in seguito dipinte in rosso, lasciando gli stessi conci a vista. Il paramento esterno presenta conci di dimensioni diverse, pezzi rettangolari e più grossi 


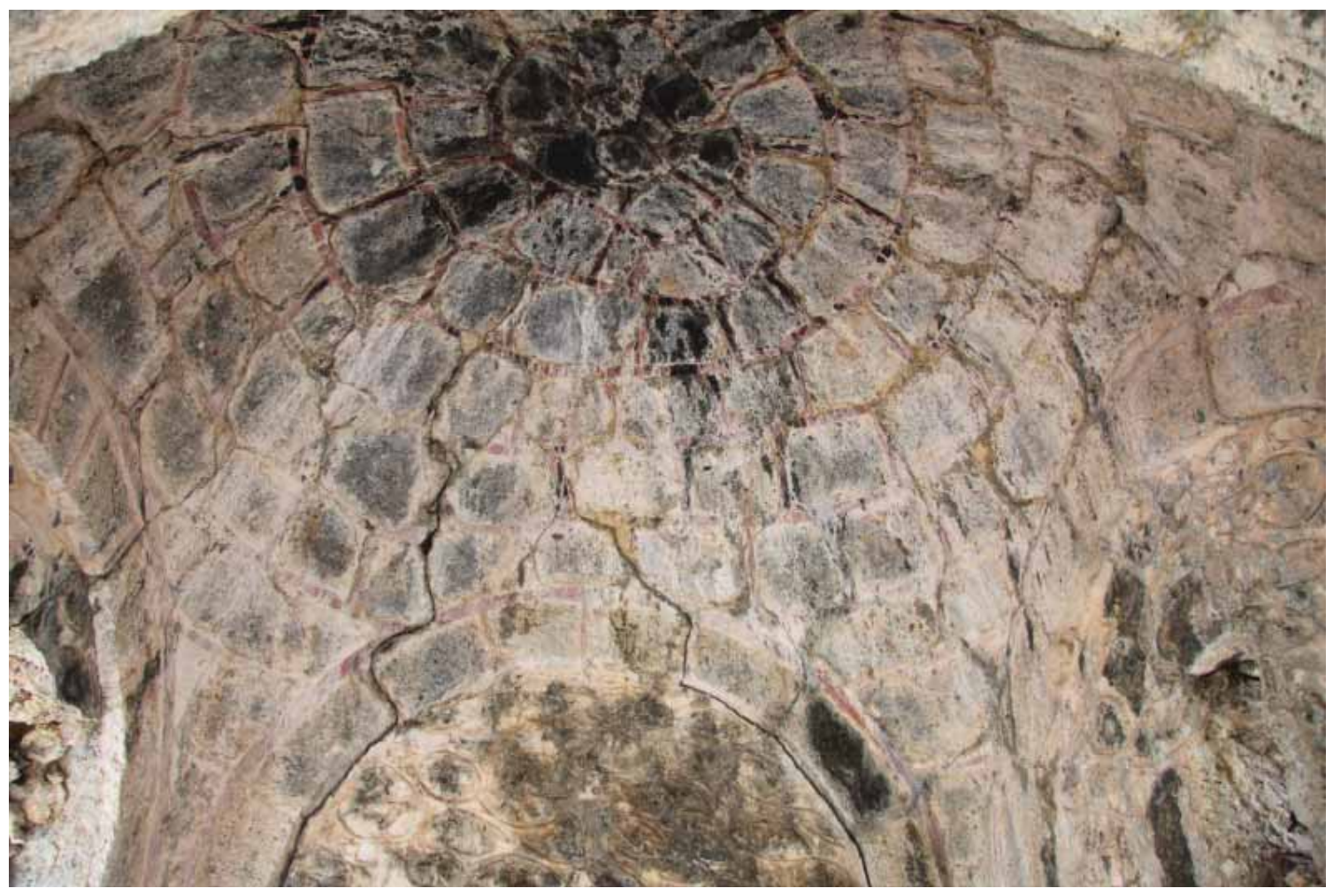

Foto 5. Ge5, tomba a croce. Vano centrale, l'interno.

sono impiegati per gli angoli, mentre gli archi accolgono conci più squadrati e curvi. Nei giunti tra $i$ conci si vede l'impiego occasionale di frammenti laterizi. La cupola e parte del tamburo esterno erano coperti con uno strato di cocciopesto. Alla costruzione iniziale, addossato all'arco sud, viene aggiunto un vano rettangolare, più stretto, a formare un ingresso a forma di corridoio voltato. Quanto si prospetta oggi del corridoio, è che la sua volta è a sesto ribassato e con l'imposta che parte dalla stessa quota dell'arco sud.

In un momento posteriore, la sezione meridionale dell'edificio subisce un intervento murario di una certa consistenza. L'arco centrale sud viene completamente tamponato, le murature del corridoio ricevono un rafforzo del facciavista interno ed ancora la stessa volta del corridoio viene ribassata. Restano costanti, tuttavia, tutte le murature, sia del corridoio, sia del riempimento dell'arco sud che del rinforzo all'interno, coperte con uno strato dello stesso tipo di malta e con un identico tipo di stilatura a forma sinusoidale.
Probabilmente è da ascrivere a questo secondo momento il tamponamento degli altri tre archi del nucleo, lasciando come unica fonte di luce su ogni lato una finestrella rettangolare. Le murature del riempimento degli archi sono invece in opus incertum con pezzame più piccolo e irregolare.

Una ulteriore fase è data dalla costruzione di un vano aggiuntivo a nord e dal proseguimento murario del corridoio d'ingresso, evidente da come i nuovi muri si appoggino direttamente ai precedenti senza un minimo tentativo di giuntura. Questo vano è rettangolare in pianta e coperto da una volta a botte il cui intradosso nel culmine coincide con quello dell'arco nord del vano principale, ma non nell'andamento perché irregolare. La sua muratura è simile in gran parte a quelle precedenti, ma quella della volta merita una nota aggiuntiva. Anch'essa, dall'imposta fino ai suoi reni presenta un opus quadratum, con abbondante impiego di zeppe laterizie; la sezione sommitale, invece, è costituita da blocchetti e scaglie, cementati con molta malta e posti radialmente. L'esterno 


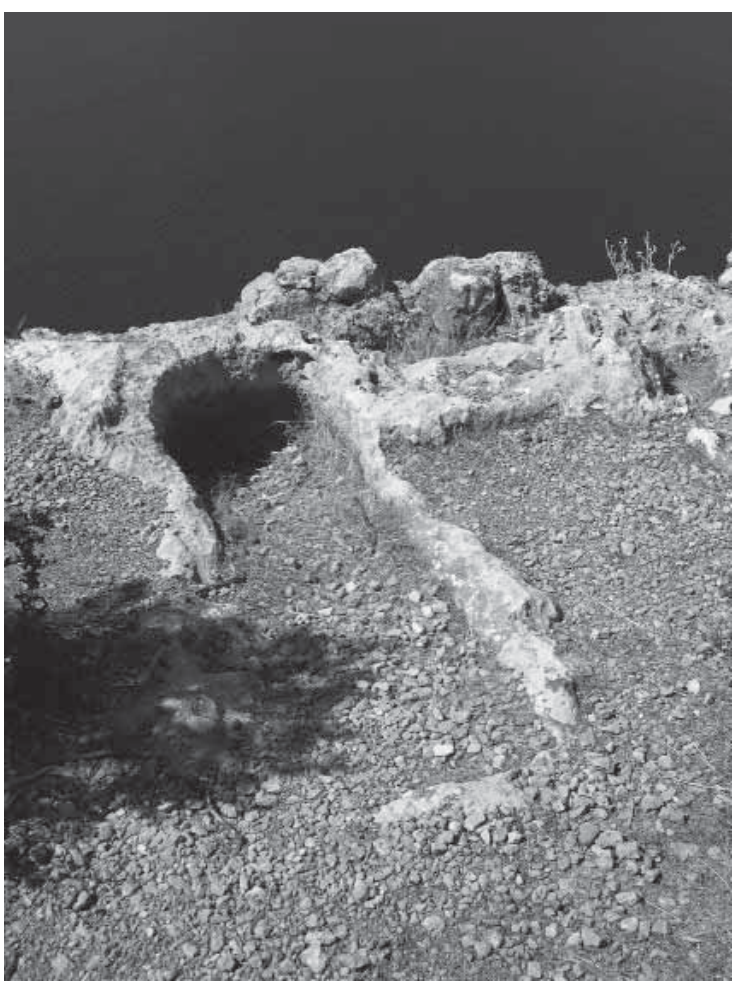

Foto 6. Gemile, una tomba a chamosorion.

Prima necropoli.

della volta è a due spioventi, coperto come di consueto da uno strato di cocciopesto.

La parte centrale dell'edificio con la cupola risponde all'altra tipologia intravista in $\mathrm{Ge} 1 \mathrm{e}$ Ge2. Le dimensioni delle tre tombe a cupola si mantengono quasi identiche. Inoltre, la presente come Ge2 mostrano un aggetto con due bracci esterni all'ingresso, espediente non rinvenuto nella Ge1, pur se essa conserva forse gli scalini di accesso. In più, la tomba in esame mostra l'unico ingresso monumentale, scavato sempre sulla stessa piattaforma in roccia, all'ingresso del corridoio voltato.

\section{TOMBE A KARACAÖREN}

Mentre le necropoli urbane di Gemile hanno una loro collocazione urbana relegata su aree quasi staccate dai plessi abitati e viabili, le differenti forme di tombe sull'isoletta di Karacaören sono sintomo, invece, dell'importanza e particola-

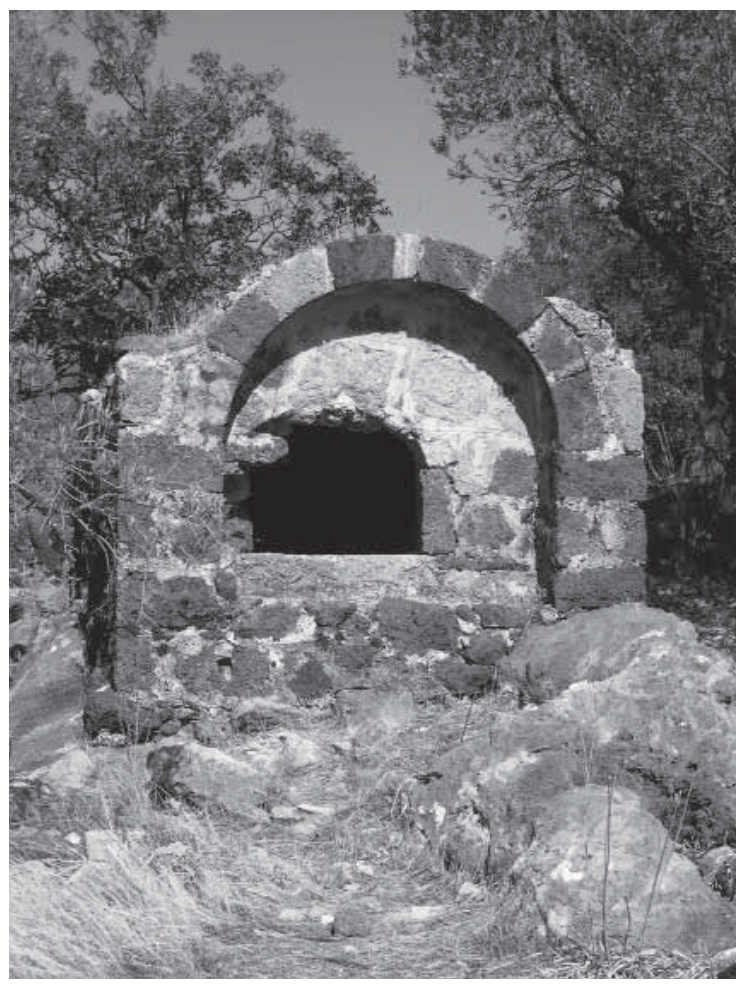

Foto 7. Gemile, una tomba a camera.

Necropoli orientale.

re natura che l'isoletta ha assunto nell'espansione della città. Karacaören è un piccola isola a forma di triangolo, distante da Gemile ca. 1 miglio e da Yarým Adasý, posta sulla terraferma ca. $200 \mathrm{~m}^{13}$.

\section{Tomba ad esedre (Ka1, fig. 7)}

La tomba Ka1, convenzionalmente chiamata ad esedre, si trova sul picco roccioso più alto dell'isola, posta a nord-est rispetto alla basilica, e su una quota leggermente superiore a questa. Vi si accede attraverso una scala, scavata appositamente nella roccia (foto 9). A parte la posizione,

13 L'insediamento posto su Yarım Adası include anche un piccolo sepolcreto di semplici chamosoria. Una sola tomba, isolata presso il lato sud della chiesa, presenta una tipologia probabilmente a cassone. Non v'è traccia della copertura, ma il loculo è costruito con cura con piccolo pezzame e malta. La pianta della chiesa a tre navate meriterebbe un discorso a parte a causa del singolare disegno ad archi che abbelisce la navata meridionale. Su questo cf. Ruggieri 1993, 398-399; Hellenkemper und Hild 2004, 600 . 


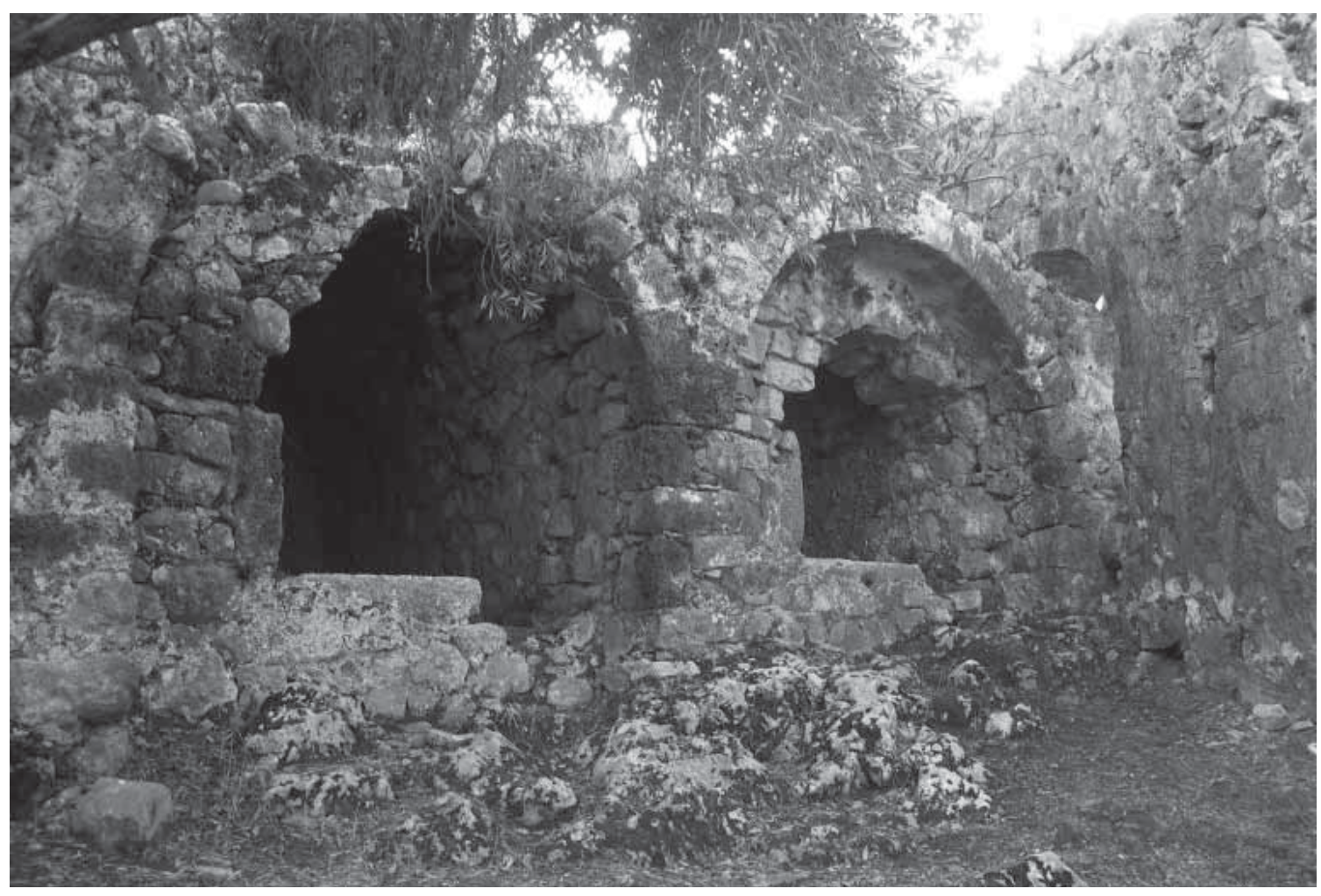

Foto 8. Gemile, tomba a camera doppia che con una parte "entra" nel corridoio voltato.

la presenza della salita a gradini appositamente approntati lascia intendere il collegamento molto stretto di questa sepoltura con la chiesa d'accanto. Infatti, alla scala si accedeva direttamente dalla porta della navata settentrionale ${ }^{14}$.

La tomba è a pianta quadrangolare, di ca. $4.35 \mathrm{~m}$ per $4.60 \mathrm{~m}$, con quattro esedre semicircolari poste all'esterno di ogni lato e con unico vano all'interno. Le dimensioni dell'esedre variano, quelle sui lati più corti dell'edificio (est e ovest) sono più piccole rispetto a quelle poste a nord e sud. La situazione di crollo dell'edificio rende problematico stabilire le loro altezze, inoltre, la quota di calpestio non risulta facilmente recuperabile su una base rocciosa solo parzialmente regolarizzata. Delle murature preservate si rileva con relativa certezza l'altezza dell'esedra ovest, ove

14 L'accesso all'area chiesastica avveniva da sud-sud-est per il tramite di scale che dall'approdo portava all'area sud-est adiacente all'annesso sud della chiesa. Un altro accesso è presente anche sul versante nord, dove una scala, lasciando delle strutture non identificate, conduceva verso il sommitale roccioso. è posta l'apertura al monumento, e con sicurezza quella dell'esedra nord. Si sa anche che le semicupole ad est e ad ovest erano certamente più alte di quelle sui lati opposti. Allo stato attuale del monumento, tuttavia, non è possibile offrire un disegno certo di tutto il sistema di copertura, anche se è da riflettere sulla copertura a due leggeri spioventi.

Al monumento si accede attraverso un ingresso posto al centro dell'esedra ovest, oggi in gran parte distrutta. Il crollo rovinoso di questo lato non consente di ricavare un'immagine certa su come l'ingresso fosse foggiato. L'interno, totalmente affrescato, è rettangolare, di ca. 2.25 per $1.35 \mathrm{~m}^{15}$. La fossa è leggermente spostata verso il lato interno sud (fig. 7). I suoi lati mostrano in parte l'apparecchio murario in blocchetti di calcare rozzamente squadrati e cementati con evidenti sbavature di malta, e parzialmente il fondamento roccioso. L'accesso all'interno si avvaleva di due piccoli gradini che immettevano sullo stretto ca-

15 Accenni su questo ciclo in: Ruggieri - Turillo 2007, 124-135. 


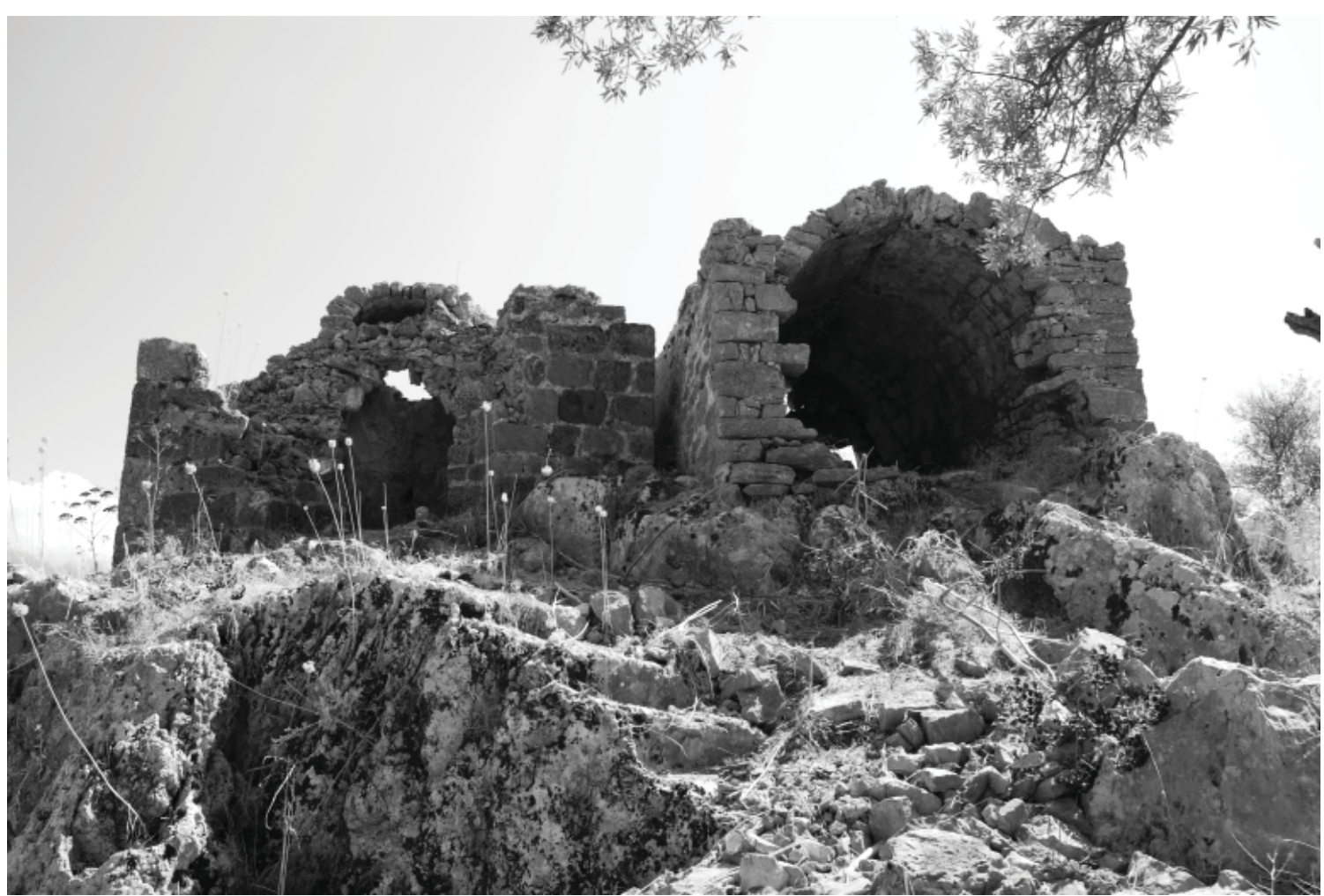

Foto 9. Ka1, tomba a esedre, e Ka2, tomba a camera da ovest con le scale d'accesso.

mminamento lungo il lato nord. A giudicare dalla fossa che ha messo in luce parzialmente la roccia è possibile che lo stesso possa dirsi per l'intera pianta della tomba, cioè che si appoggi direttamente su questa.

Mentre l'interno della muratura è alzato con tecnica in cementizio, con il ricorso a pietrame e schegge laterizie cementate con molta malta e senza una specifica posa, per la cortina muraria a vista delle esedre, invece, si è fatto ricorso a conci di calcare tagliati regolarmente e posti su un letto di malta e con una buona posa orizzontale. I conci sono di grandezza quasi costante in buona posa, un apparecchio che riprende completamente la tipologia riscontrabile nelle tre absidi della basilica adiacente e dell'annesso sud e la specificità tecnica di questi apparecchi sta nella valorizzazione cromatica delle commettiture che sono dipinte in rosso creando un bel contrasto col colore naturale della pietra grigio scuro ${ }^{16}$. Per quanto riguarda,

16 In un caso (Ruggieri 1999, 300-301) si ha la stessa resa cromatica sulla conca di una tomba, ma i giunti dipinti invece, la muratura dei poderosi angoli esterni, vengono usati blocchi molto grandi alternati con quelli piccoli, senza un rispetto canonico delle assisi lungo i quattro versanti. Di tutta la muratura sembra che la tecnica versata sulla volta sia la meno curata, costituita da blocchetti poligonali rozzamente lavorati, schegge litiche e pezzame diverso posti in posa radiale e legati con abbondante malta. Dato che quasi tutto l'interno reca ancora l'affresco con lo strato di intonaco, non è evidente dove e come si armava la centina, né se per la stesura della volta si sia fatto ricorso all'armatura lignea (foto 10).

La posizione di questa tomba sul picco roccioso sovrastante la chiesa certamente aveva un legame particolare con la stessa basilica: costruite nello stesso tempo, e questo è da dedurre non solo per loro tecnica muraria, ma anche per la tecnica e cromatismo degli affreschi che richiama perfettamente le maestranze all'opera sulla chiesa. Al

non rispondevano alla vera disposizione delle pietre sottostanti. 


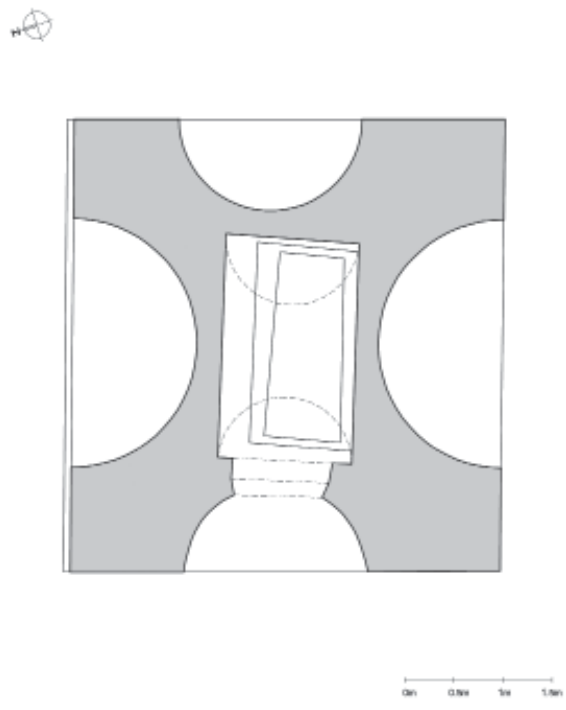

Fig. 7. Ka1, pianta.

tempo della sua costruzione, comunque, Ka1 restava sola sul picco a sovrastare la basilica; v'è stato un lasso di tempo dopo il quale si è reso necessario accostare alla tomba un terrazzamento. Questo partiva dallo spigolo nord-est della tomba e si piegava lungo tutta la parete alta del versante est in modo tale da regolarizzare l'area che si predisponeva ad accogliere altre tombe. Il terrazzamento, tuttavia, mostra una tecnica muraria che si discosta da quella della Ka1, il che, sembra, sia indice di un disegno di allestimento per un sepolcreto in un periodo quando divenne necessario più spazio a causa della richiesta di committenti.

\section{Tomba a camera (Ka2, fig. 8)}

La tomba Ka2 mostra la tipologia a camera ed è collocata accanto alla Ka1, adiacente al suo lato sud (foto 9). La sua forma è diffusa sia sulla stessa isoletta, come sull'isola di Gemile. Anche verso $\mathrm{Ka} 2$ si accede attraverso una corta scala di tre scalini scavati nella roccia sul versante sud-est, ma dalla parte opposta rispetto alla scala che conduce verso Ka1. La scala quasi certamente è stata creata nel momento in cui si è ritenuto necessario creare il terrazzamento di cui si è parlato in precedenza.

La tomba è a pianta rettangolare, con dimensioni complessive di ca. $5.10 \mathrm{~m}$ per $3.40 \mathrm{~m}$. La sua forma esterna richiama un parallelepipedo coperto con una volta a botte sovrastata da una membrana muraria a spiovente. Dall'esterno infatti, è visibile la porzione superiore della volta con le tracce murarie degli spioventi, perché l'altezza dei muri laterali sui quali essa poggia arriva fino ai reni della volta. Contrariamente alla Ka1, il prospetto principale di questa tomba è quello orientale approntato sulla terrazza creatasi per l'occorrenza. Esso si presenta con una foggia ad archivolto in aggetto con arco a tutto sesto. La fattura d'imposta dell'archivolto mostra noncuranza, affidandosi a due blocchi con altezze differenti, pur impreziositi da una semplice modanatura in aggetto (fig. 9). Al centro del prospetto est si presenta una apertura quadrangolare con piatta-

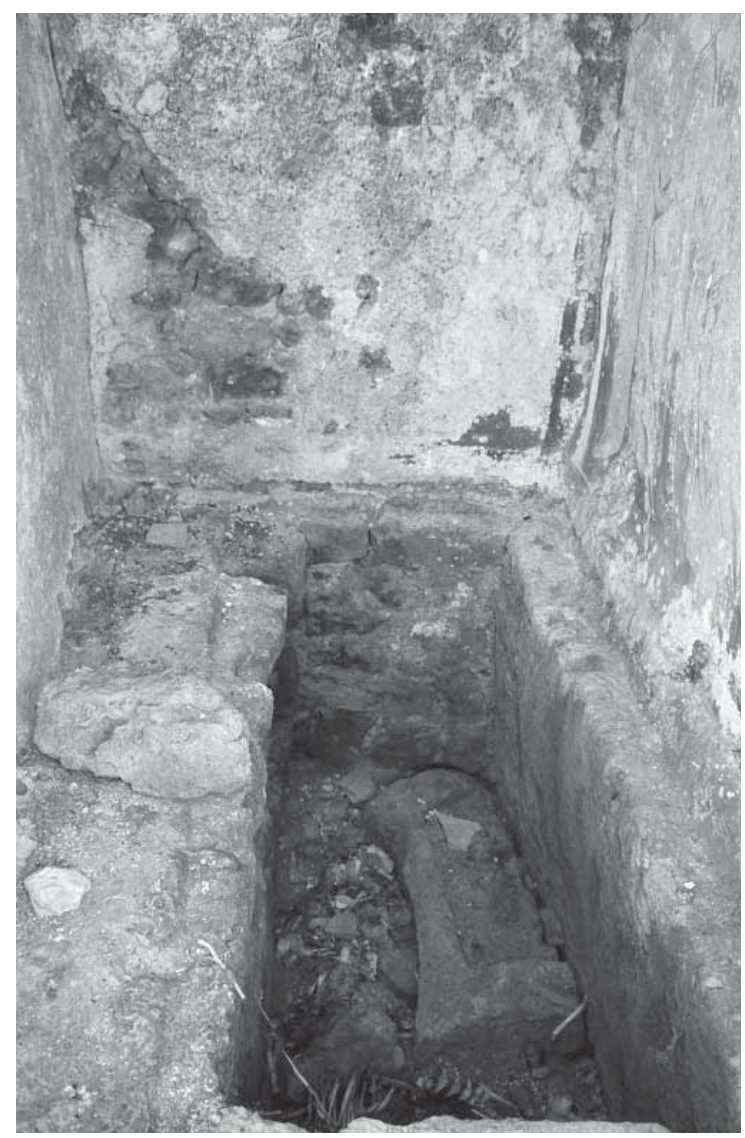

Foto 10. Ka1, tomba a esedre. Interno. 


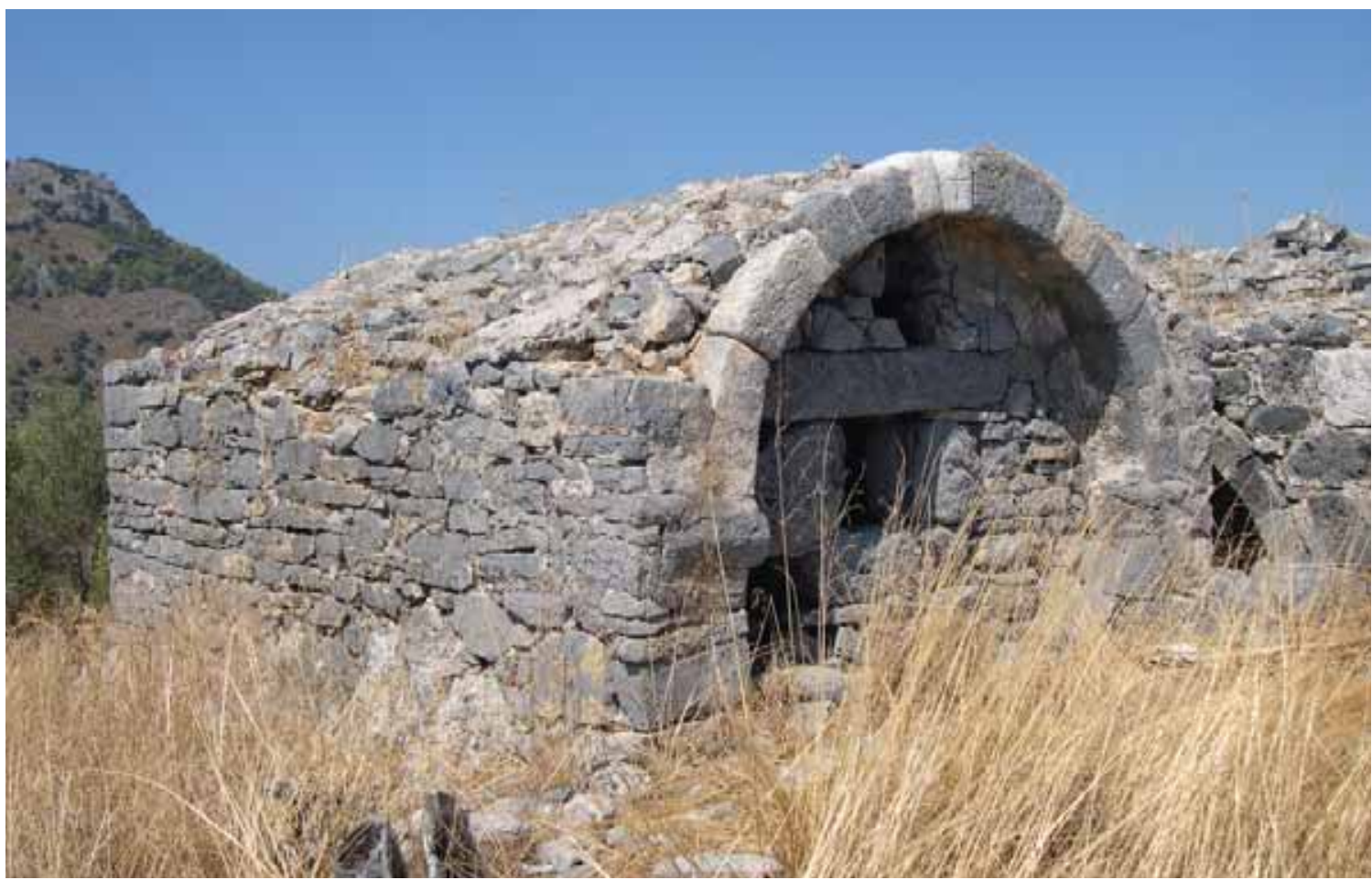

Foto 11. Ka2, tomba a camera. Prospetto sud-est.

banda calcarea, spostata leggermente verso sinistra. Questa anomalia nel rispetto della simmetria sul prospetto si affianca anche ad una scarsa cura nell'approntare il facciavista dell'apparecchio che si discosta dalla maestria dei lati lunghi. Difficile dire cosa sia accaduto sulla facciata orientale. È evidente che vi sia stato qualche ripensamento o rifacimento del muro evidenziato dal taglio e dalla posa del materiale usato, come è impossibile ricostruire una cronologia degli interventi (foto 11).

L'interno della tomba è coperto con un cumulo di terra e detriti, forse parzialmente appartenenti al crollo del muro ovest, per cui non è stato possibile individuare la posizione dei loculi, né il loro numero, né la quota. A giudicare dalle altre tombe simili è lecito supporre che aveva almeno due loculi longitudinali, uno accanto all'altro, adiacenti ai lati lunghi, e forse un terzo trasversale, posto dal lato ovest. I muri sud e nord hanno uno spessore medio di $55 \mathrm{~cm}$; sono in cementizio, con le cortine a blocchi parallelepipedi di varia forma e diverse dimensioni. Si nota che la posa dei blocchi sul lato sud è più regolare verso ovest, dove sono stati usati con più cura $i$ conci di forma rettangolare allungata. La volta ritorna all'uso di scaglie calcaree poste radicalmente con una certa regolarità. Da quanto detto si evince come la maestranza al lavoro era diversa da quella richiesta dalla Ka1. L'edificio posa direttamente sulla roccia e sovrasta in altezza la tomba Ka1.

La facciata est una volta era affrescata: si sono mantenute tracce dell'intonaco dipinto sotto l'archivolto, sia dalla parte sinistra, che a destra; ambo le tracce si riferiscono a croci. Le pareti interne conservano larghi tratti di intonaco, facendo cosi supporre che anche in questa sepoltura si dispiegasse un ciclo pittorico. Le tracce di valorizzazione dei giunti dipinti in rosso, presente nella Ka1, si vedono ben netti anche lungo la curva esterna dell'archivolto della facciata principale; si sono perfettamente conservate tracce delle incisioni, mentre del colore restano solo sparuti frammenti.

Il terrapieno che collega la tomba Kal e $\mathrm{Ka} 2$ nell'area antistante queste due tombe, delimitate dal muro est del terrazzamento, reca ancora 


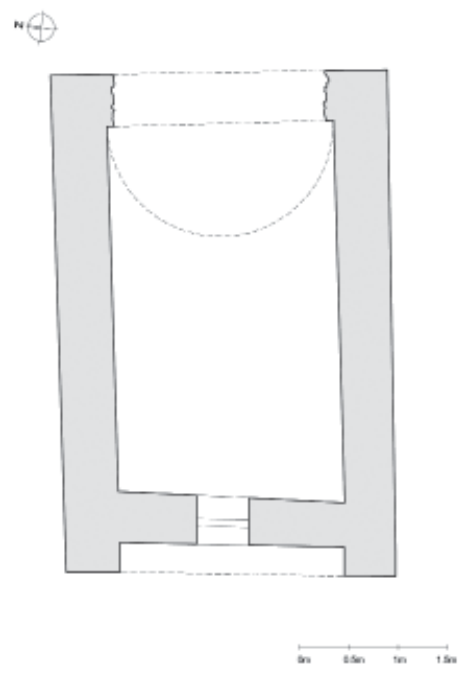

Fig. 8. Ka2, pianta.

delle tracce murarie a terra di difficile identificazione. Quasi certamente quest'area di ca. 6 per $12 \mathrm{~m}$ ospitava altre tombe accessibili dalla scala a gradini che saliva da sud. Questo picco roccioso, dunque, nasce originariamente come sede di un'elegante sepoltura e diviene nel corso di pochi decenni un luogo privilegiato di sepolture, vicini fra loro e soprattutto accanto alla Ka1 che viene in questo modo circondata, pur conservando il suo proprio accesso da ovest. A nord, invece, sotto il terrapieno, la caduta di quota è quasi immediata; sul primo sbalzo si è ricavato spazio per due semplici sepolture a fossa che hanno utilizzato la regolarizzazione della roccia e poca muratura di rincalzo sul versante nord. Alla seconda caduta di quota, su una protuberanza rocciosa, quasi aggrappata alla parete di roccia sovrastata dal terrapieno, si trova Ka3.

\section{Tomba pseudo-ellenistica 1 (Ka3, fig. 10)}

La tomba Ka3, chiamata convenzionalmente prima pseudoellenistica, è posta sotto il terrazzamento della Ka1 addossata alla roccia, e appare isolata dal gruppo funerario soprastante

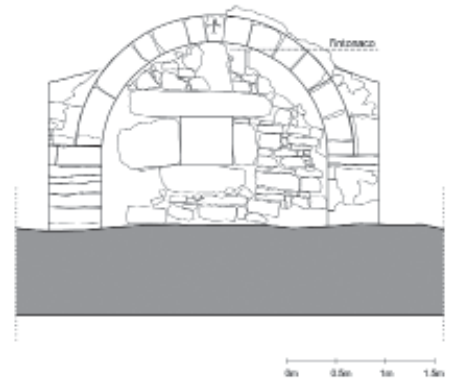

Fig. 9. Ka2, prospetto est.

(fig. 11). Oggi non si sono preservate le tracce di alcuna scala di accesso e se ve ne fosse stata una, probabilmente si sarebbe trovata sul lato del suo prospetto principale, ovest. Questa tomba mostra tutto il suo aspetto monumentale dal lato nord ed est visibile venendo dal mare, dove l'apparecchio murario in opus quadratum, sormontato dagli spioventi, pubblicizzava una committenza di un buon ceto sociale. Tra il gruppo presso il picco roccioso questa tomba è la più distaccata dalla Ka1, ma la volontà di essere accanto al centro propulsore di un certo interesse per l'isola ha indotto gli operai ad un lavoro improbo e delicato.

La pianta della struttura funeraria è di forma quasi rettangolare e le sue dimensioni complessive sono di ca. $3.30 \mathrm{~m}$ per $2.80 \mathrm{~m}$. L'edificio è di forma a parallelepipedo a due spioventi con un suo lato più lungo, il meridionale, addossato al pendio del picco così che gli spioventi sono paralleli a questo. Gli spioventi partono dall'altezza del cuneo mediano della stessa volta. In seguito un intervento ha riempito il volume intercorrente dall'originale spiovente sud al terrazzamento roccioso, creando all'esterno una superficie obliqua probabilmente per canalizzare l'acqua piovana da quella parte. Il prospetto principale, quello occidentale, è in parte crollato. Si osserva che aveva all'ingresso un'apertura rettangolare. A giudicare della tracce quasi certamente il vano sepolcrale era chiuso ad ovest da una lastra monolitica. Accanto a questa, dal suo lato sinistro, v'è una mensola con listello piatto. L'interno della tomba ospitava tre loculi (foto 12): due più grandi, uno accanto 


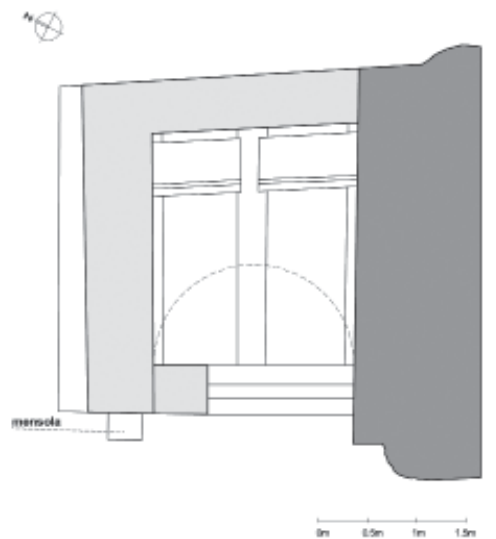

Fig. 10. Ka3, pianta.

all'altro posti longitudinalmente occupando tutto l'interno e in fondo, dalla parte opposta all'ingresso, sopra le due lastre che coprivano la sezione est di questi, si approntò il terzo loculo, in direzione trasversale.

Per la costruzione della tomba fu prima creato un terrazzamento sulla roccia, regolarizzandola con taglio e in seguito con i getti di materiale edilizio. Per la costruzione del lato sud, quello addossato al pendio, è stata creata anche una preparazione in muratura. Lo zoccolo sul lato nord in parte è perfettamente scolpito nella roccia e lo stesso all'interno coincide con il culmine del letto funerario. È quindi probabile che viene sfruttata la roccia dove possibile, e dove non lo era, si è semplicemente proceduto alla costruzione in muratura o con getti. La tecnica muraria, a sacco, ha i paramenti a vista esterni in opus quadratum e quello interno ha fatto ricorso a blocchi irregolari con molta malta nei giunti. Lo spessore dei muri non è perfettamente uniforme e corre da 50 a $70 \mathrm{~cm}$. La volta a botte fu realizzata con listelli, schegge e pietrame posti più o meno radialmente e cementati da un abbondante strato di malta; non si è notato l'impiego di frammenti laterizi. L'interno fu coperto con uno strato di arriccio i cui resti sono ancora visibili. Volendo proporre, pur se ipoteticamente, una sequenza di questo primo gruppo di tombe, basandosi sull'evoluzione della

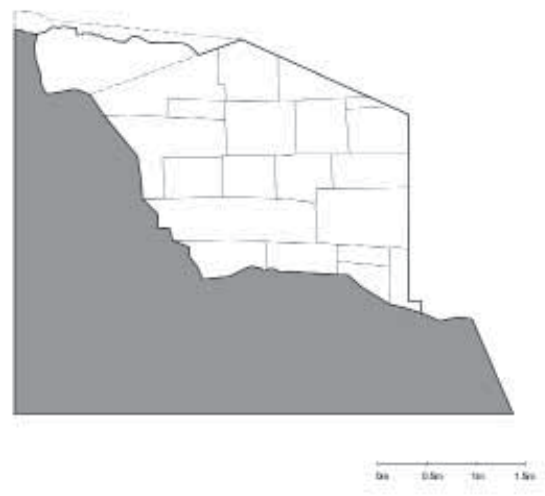

Fig. 11. Ka3, prospetto est.

ristretta area funeraria, si potrebbe pensare che la $\mathrm{Ka} 1$ sia coeva con la chiesa; la Ka3, nel rispetto del picco roccioso ove posa la Ka1, segue di presso; la Ka2 e le altre vicine si pongono alla fine della sequenza delle sepolture su quest'area.

\section{Tomba a sarcofago licio (Ka4, fig. 12) ${ }^{17}$}

La tomba Ka4, chiamata a sarcofago licio per la sua forma esterna ad ogiva (foto 14), è situata nei pressi della basilica, a sud-est rispetto all'abside. Di fronte alla tomba Ka5, che si posa su una quota più bassa, questa piccola tomba è situata lungo il pendio roccioso con un orientamento est - ovest. Le sue dimensioni complessive, pur nella irregolarità della pianta, sono di ca. $3.55 \mathrm{~m}$ per $1.95 \mathrm{~m}$. La pianta è a forma allungata, absidata sul lato nord-est, opposto all'ingresso; la forma a sarcofago rende lo spazio della sepoltura piuttosto trapezoidale con il suo lato più largo verso l'ingresso, irregolarità percepibile anche ad occhio. Anche l'absidiola è pseudocircolare, schiacciata dal muro di chiusura. La tomba ospita un loculo rettangolare, incassato nella roccia, sulla quale

17 La tomba richiama una tipologia già affrontata su Gemile. L'aver scelto un altro esemplare, pur se parzialmente crollato nella volta, fra altri di ben più preservata fattura, è dovuto alla presenza dell'esedra antistante, una particolarità non riscontrata (forse perché non preservata?) negli altri casi. 


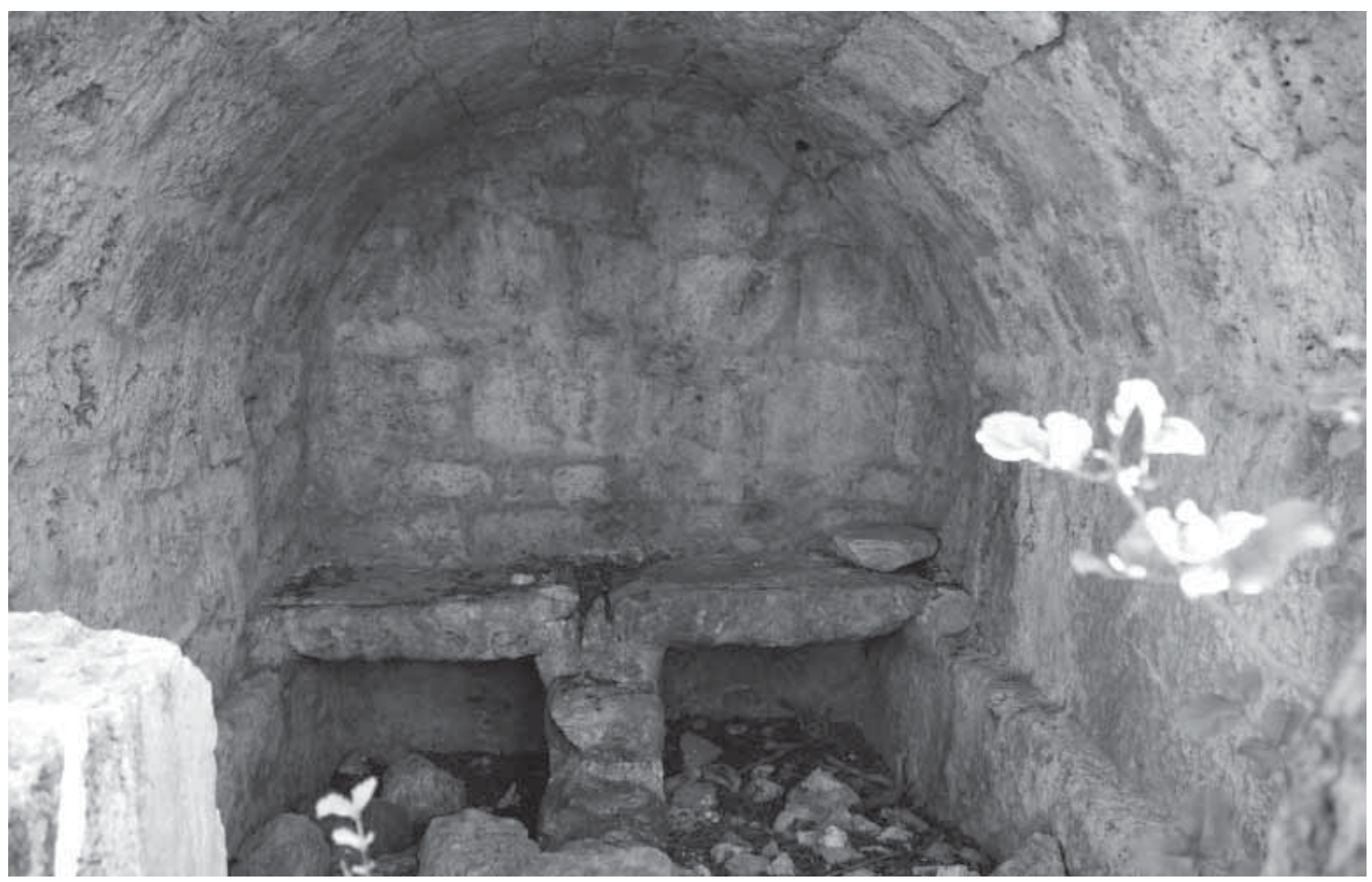

Foto 12. Ka3, prima tomba pseudoellenistica. Interno.

posa la parte muraria della tomba. Davanti all'ingresso, oggi crollato, ci sono i resti di una piattaforma, forse semicircolare, in roccia sagomata.

La soluzione della volta ad ogiva è specifica: la curvatura si impostava subito dalla base esterna del loculo, pur se è più percepibile solo a metà della sua altezza. Dall'esterno, invece, i muri laterali restano eretti fino alla metà della volta, conservando un discreto piombo e lasciando visibile solo la porzione superiore più ogivale della volta. Non ci sono dati per ricostruire il suo prospetto principale, né si rinviene un esempio in loco di questa tipologia che abbia conservato degli indizi certi. Lo spessore della muratura non è uniforme e corre dai 35 ai $55 \mathrm{~cm}$ per i muri laterali mentre quello dell'abside risulta $45 \mathrm{~cm}$. La muratura è in opus incertum, composta di conci di pietra di varia misura, pietrame, frammenti laterizi e cocciame affogati in molta malta ${ }^{18}$. La facciata

18 In un altro esemplare di tomba simile, ad ovest della chiesa, la muratura esterna si affida a conci ben tagliati e messi in posa con perfetto piombo. Un altro ancora mostra parte della lastra di chiusura (4-5 cm di spessore) che si appoggiava sui bordi creati all'esterno del loculo sud che sovrasta il pendio e guarda il mare è di pessima fattura: si direbbe un raffazzonatura muraria di cattiva esecuzione.

Benché questa tomba non eccelle in qualità, è ben visibile grazie alla sua posizione. Gli altri esempi di questa tipologia presente su Karacaören sono posti su un podio roccioso e, quando la roccia lo richiedeva, si rabberciava la base con muratura. Una qualità di questa tipologia era dunque la sua visibilità nella pur esile linea della costruzione, lontana dalla massiccia tomba a camera.

\section{Tomba pseudoellenistica 2 (Ka5, fig. 13)}

La tomba Ka5, la seconda pseudoellenisti$c a$, è posizionata a sud della basilica di cui è leggermente distante e autonoma, su uno dei pendii più scoscesi dell'isola. Ad essa si accedeva attraverso tre scalini, come di consueto scavati nella roccia, che giungono sulla piattaforma esterna di accesso a forma circolare. Benché non molto grande, le dimensioni complessive esterne misu- 


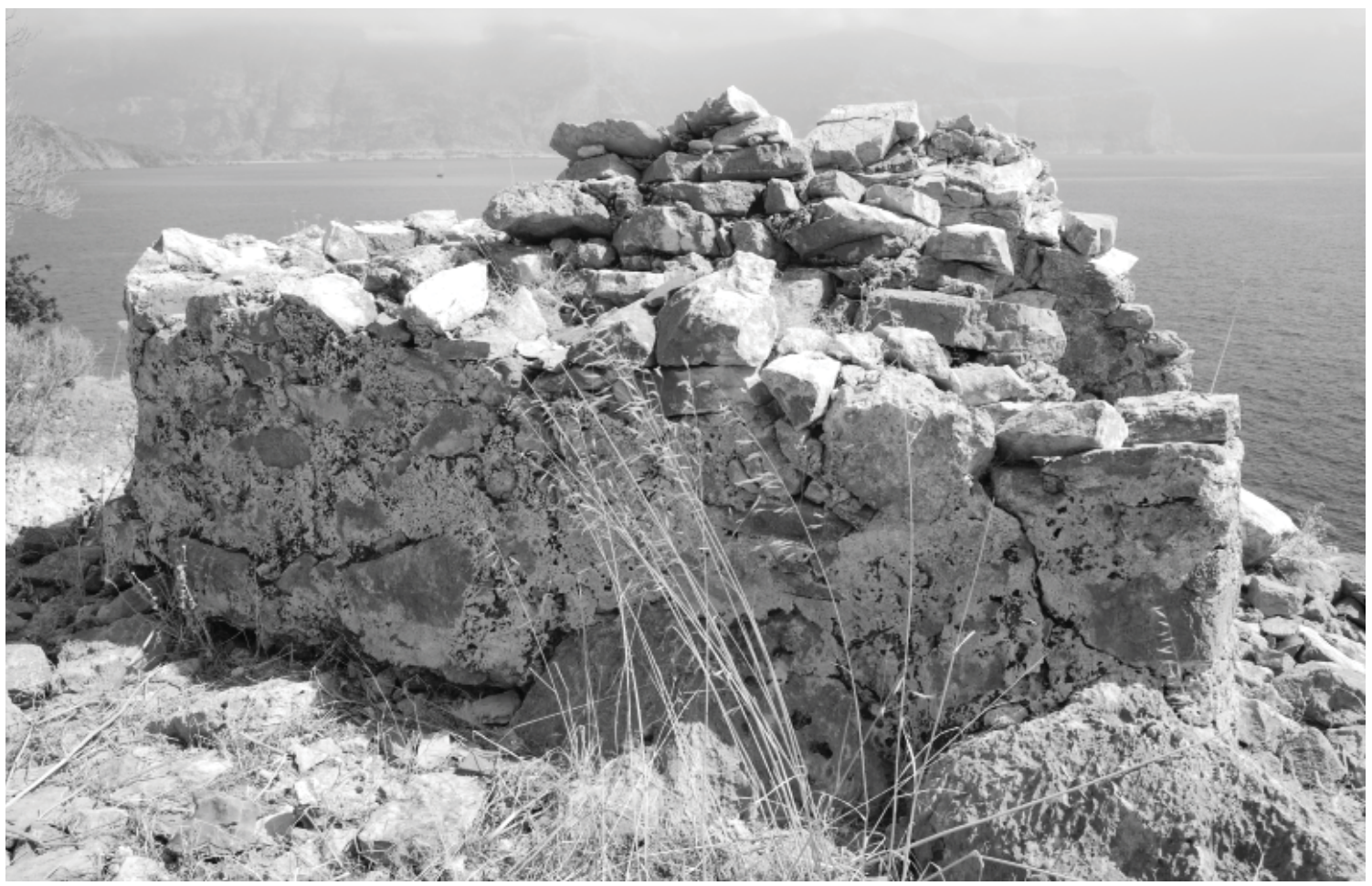

Foto 13. Ka4, tomba a sarcofago licio. Prospetto nord.

rano ca. $4.00 \mathrm{~m}$ per $2.70 \mathrm{~m}$, era sicuramente ben visibile a chiunque tentasse ad avvicinarsi all'isola dal lato sud, grazie alla sua posizione.

La tipologia della tomba è particolare e rappresenta l'unico esempio di questo genere nell'architettura sepolcrale in tutta la zona. La sua forma parallelepipeda in pianta rettangolare è addolcita grazie ad un'esedra antistante e alla cupola con la quale era coperta. Sebbene una buona parte superiore dell'esedra oggi è carente, sembra che originariamente chiudeva in sommità con una semicalotta (fig 14). Quello che oggi rimane della sua plastica esterna è una cornice sotto il concio d'imposta sinistro sul prospetto principale e il frammento di un fregio sul lato sud ambedue a listello piatto. All'interno si accedeva attraverso una piccola apertura rettangolare, una volta chiusa da una lastra.

Le dimensioni del suo interno sono: i lati più corti (est e ovest) variano dal $1.65 \mathrm{~m}$ al $1.47 \mathrm{~m}$ e quelli più lunghi (nord e sud) dal $2.15 \mathrm{~m}$ al 2.25 $\mathrm{m}$. Nella tomba sono scavati due loculi in senso longitudinale, a giudicare dalle dimensioni dei letti funerari (fig. 13). All'interno, sul dado paralle- lepipedo si imposta una cupola a vista. La tomba doveva essere complessivamente alta all'interno sui $3.80 \mathrm{~m}$. Benché la cupola poggi su una base leggermente allungata, la sua forma risponde meglio ad una forma quasi circolare. Come raccordo tra la base quadrangolare e quella ellissoidale anche qui si è ricorso ai pennacchi, con non poche irregolarità di simmetria. Per accorciare l'asse più lungo, il muro dei lati più corti viene inclinato verso l'interno, a partire dal livello degli stessi pennacchi. Da questo punto parte la curvatura che corre verso il sommo della cupola. Le sommità di questi rudimentali pennacchi vengono poste ad altezze diverse con la risultanza che la base de1la cupola non è perfettamente orizzontale ${ }^{19}$. La cupola, in aggiunta, è irregolare anche nella sua sezione verticale, a dire, semiovale.

L'intera sezione del letto funerario è stata ricavato dalla roccia; ancora, gran parte del muro interno a nord-est ripropone la roccia viva che si alza fino alla base del pennacchio est. Alla roccia

19 Il "pennacchio" nord-ovest è completamente scavato nella roccia. 
scolpita si sovrappongono i muri, realizzati con la tecnica in cementizio (foto 14). Il paramento esterno a vista è in opus quadratum con i blocchi in grandi e varie dimensioni e con tagli d'incastro fra i blocchi; per l'interno si è fatto ricorso a blocchi più uniformi nel taglio posti in buone assisi con regolari giunture. I muri sono riempiti con normale cementizio e per la calotta della cupola viene impiegato all'esterno sempre un opus incertum, mentre l'interno è alzato con blocchetti, senza indizi sulla sua rifinitura. Nei crolli si vedono ancora i resti di malta usata abbondantemente con l'impiego di laterizio e cocciame.

La tomba Ka5, vista da lontana, inducesse ad essere ritenuta ellenistica (foto 15); questa pretesa, ad una attenta analisi, invece viene relegata al tempo cristiano e si constata come la fusione della cupola su un corpo parallelepipedo si risolve costruttivamente in modo maldestro. Certamente è da ascrivere a questa tomba una sua eleganza esterna: l'esedra di facciata in alto e l'altra a terra davanti all'ingresso, un espediente visto davanti ai sarcofagi su podio sparsi a Üçağız (Tristomon) che ne hanno fatto un unicum architettonico nel territorio.

\section{Tomba a camera doppia (Ka6, fig. 15)}

La tomba Ka6, chiamata a camera doppia, si trova in un'area funeraria collocata distante dal-

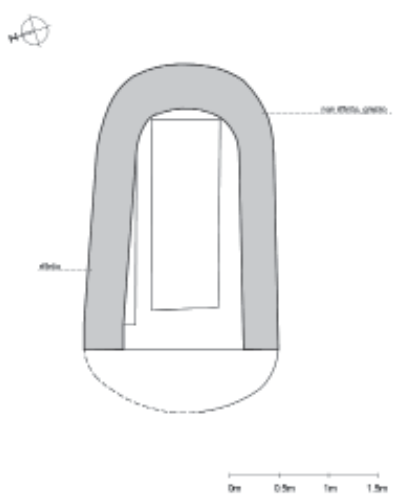

Fig. 12. Ka4, pianta.

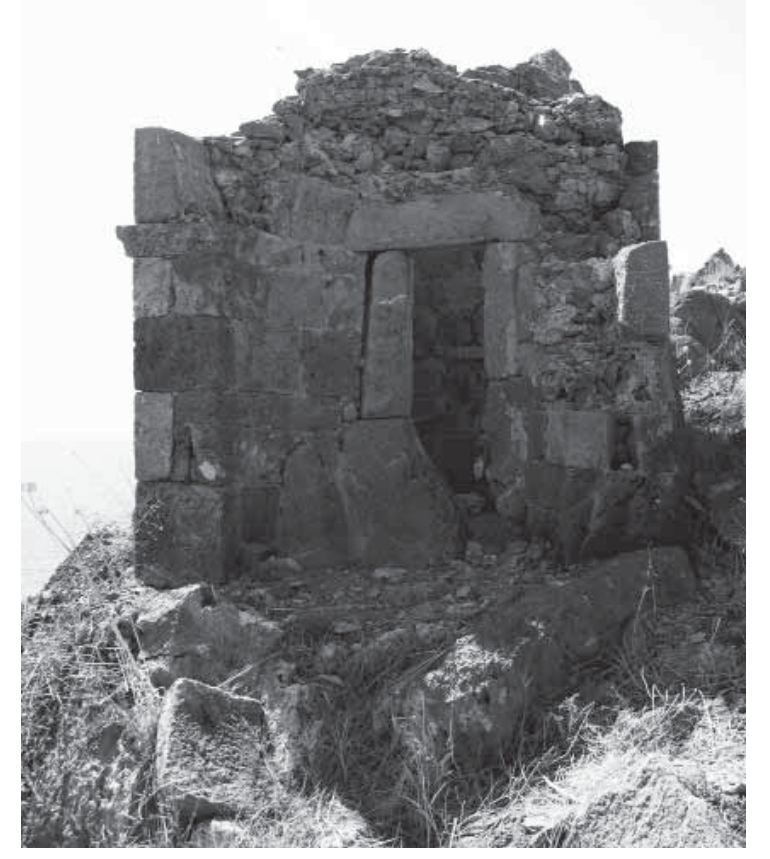

Foto 14. Ka5, seconda tomba pseudoellenistica.

Prospetto est.

la chiesa, verso nord-ovest, al di là di una serie di ambienti abitativi. Essa presenta una variazione della tipologia a camera, creata raddoppiando due tombe identiche, poste accanto ed aventi un muro divisorio longitudinale in comune (foto 16$)^{20}$. In forza di questo raddoppio, le sue dimensioni sono elevate: ca. $6.50 \mathrm{~m}$ per $4.45 \mathrm{~m}$, con pianta abbastanza regolare. Tutto quanto detto circa la forma esterna della Ka2 vale anche per questo caso, con alcune differenze. Il prospetto principale presenta due aperture rettangolari con una mensola posta al centro, simile a quella presente nella Ka3. Il prospetto principale è parzialmente crollato e non si puo essere certi sulle dimensioni delle aperture; restano ancora solo gli scorrimenti verticali ancora ben leggibili lungo gli stipiti. Ciò che impressiona di questa tomba è la sua imponente mole visibile già dalla possente presenza di blocchi negli angoli e nel prospetto principale. Anche in questa situazione, si notano bene le spalle murarie esterne che sostenevano la spinta della volta e il leggero

$20 \mathrm{Si}$ potrebbe ipotizzare che si tratti di una tomba di famiglia considerando che contiene in totale sei loculi, tre per ogni camera. 


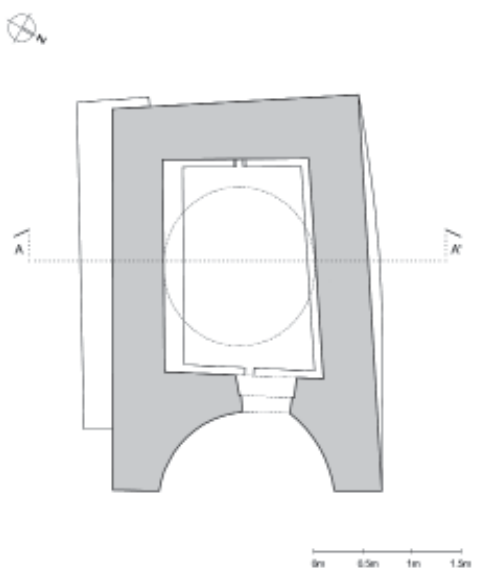

Fig. 13. Ka5, pianta.

piano inclinato ancora percepibile degli spioventi sovrastanti (foto 17). La facciata est di ambedue presenta due piccole aperture poste ognuna sotto il concio di chiave del rispettivo arco (fig. 16).

All'interno di ogni camera i loculi vengono posti nella seguente maniera: due addossati alla facciata principale paralleli alle generatrici della volta e il terzo, più stretto, collocato al fondo posto trasversalmente. La divisione degli spazi interni avviene pel tramite di muretti. Come al solito, la tomba è carente di fondazioni. Le murature sovrapposte alla roccia vengono realizzate con un sacco in cementizio con presenza di frammenti laterizi. I conci del paramento murario esterno sono in opus quadratum, con blocchi poligonali di dimensione diversa ma comunque grandi e in posa abbastanza regolare, ad eccezione della parte inferiore del muro nord ed est dove sono presenti conci più piccoli con taglio non uniforme. Per il facciavista del muro interno est, invece vengono impiegati $i$ conci più piccoli in vari tagli e dimensione (foto 18).

\section{CONSIDERAZIONI ARCHITETTONICHE FINALI}

Generalmente le tombe presenti nelle due isole si possono distinguere in due tipi: il primo è il semplice letto funerario scavato nella roccia,

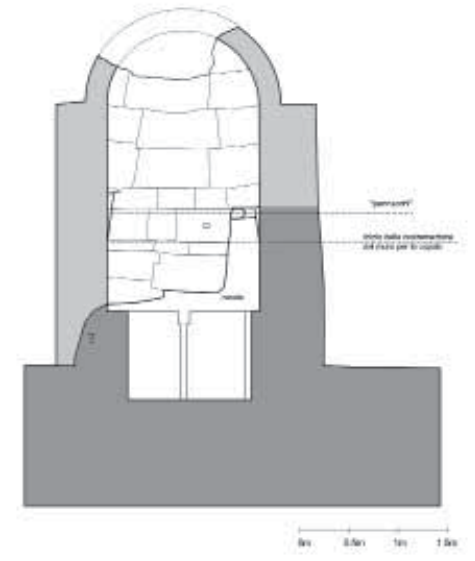

Fig. 14. Ka5, sezione AA.

cioè il chamosorion ${ }^{21}$; il secondo presenta una costruzione in muratura sovrastante il letto funerario. Le tombe a chamosorion erano tutte scavate nella roccia con misure che si aggiravano mediamente su ca. 1.80 per $0.60 \mathrm{~m}$ con una profondità da $40 \mathrm{a} 85 \mathrm{~cm}$ (foto 6). Probabilmente per la chiusura si è fatto ricorso ad una semplice lastra calcarea. Le tombe con le costruzioni in muratura presentano da parte loro una varietà di forme architettoniche che a volte riprendono tipologie classiche, altre volte, a quanto sembra, mostrano delle forme originali non riscontrabili altrove. La forma più diffusa è quella a camera: una costruzione parallelepipeda coperta da una volta a botte nascosta all'esterno da due spioventi ${ }^{22}$. La facciata principale di solito reca una apertura rettangola-

21 Gli studiosi giapponesi hanno fotografato sull'isola di Gemile i resti di una copertura di sarcofago a spioventi con il frontone e gli acroteria angolari, la cui collocazione esatta non è stata rilevata: "We did, in 1993, find the roof-type lid of a tomb, cut into the bedrock northeast of Church III. The marble lid that dates back to no later than the first half of the fifth century has a simple shape and is decorated with acroteria at the four corners and a cross that is carved in relief at the pinnacle of the roof.", cf. Tsuji 1996, 269 e fig. 16; forse si tratta dello stesso pezzo marmoreo la cui foto si trova in Asano 2010, fig. 185. Per un ottima trattazione sulla tipologia sepolcrale a chamosorion, cf. Equini Schneider 2003, 454-457.

22 I giapponesi solo sull'isola di Gemile hanno rilevato 122 tombe. Di queste a camera sono 58. Si veda la tabella con tutte le tombe di Gemile con i dati fondamentali tipo dimensioni, orientazione e collocazione, in Asano 2010, 144-146. 


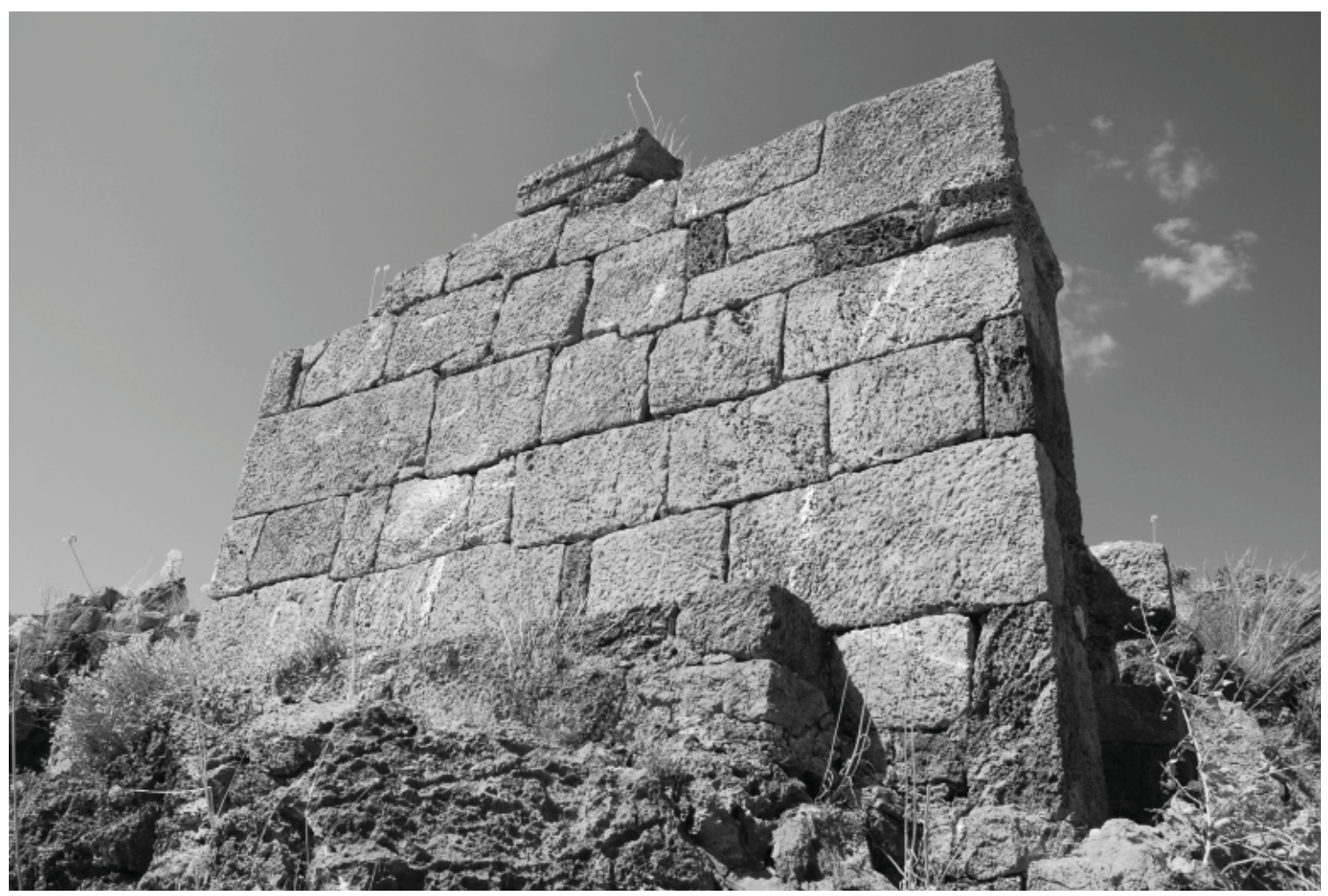

Foto 15. Ka5, seconda tomba pseudoellenistica. Prospetto sud.

re con una lastra di chiusura mediamente di ca. 60 per $90 \mathrm{~cm}$ che esclude un formale ingresso. La facciata principale poteva sostenere anche un archivolto sporgente che, sovrastando l'apertura, creava riparo agli affreschi, oggi ridotti solo in frammenti. Di rado costruita per una sola persona, la tomba a camera racchiudeva più spesso due letti funerari posti sull'asse longitudinale; vi sono anche esempi con tombe a tre loculi. Raro è il caso di tombe doppie a camera con un unico muro divisorio (Ka6 e la tomba doppia accanto al corridoio voltato di Gemile, foto 8). Un altra forma, chiamata a sarcofago licio, si basa su una vaga rassomiglianza esterna al sarcofago diffuso in questa regione in epoca classica. La somiglianza richiama la forma ogivale dell'esterno eretta nel nostro caso in muratura. Di solito le tombe di questa tipologia hanno un solo loculo (foto 19). Altre tombe hanno una forma particolare, vale a dire, il parallelepipedo con cupola e quanto chiamato "pseudoellenistico" (Ge2, Ge3, Ge5, Ka1, Ka3 e Ka5). La tomba a cupola (uno, forse due letti all'interno) come tipologia è nuova e architettonicamente mal risolta. Quanto è stata chiamata "tomba pseudoellenistica" rappresenta un nostalgico ritorno a una muratura ellenistica con soluzioni di coperture non architettonicamente riuscite.

\section{TECNICHE COSTRUTTIVE}

Tutte le sepolture erano voltate a botte e in alcuni casi con cupola. Nelle tombe a camera le generatrici della volta seguivano l'asse longitudinale; la volta impostava a circa metà dell'altezza complessiva della tomba. I muri perimetrali dell'asse longitudinale si tengono dai 50 ai 70 $\mathrm{cm}$ e il loro spessore non sempre dipende dalle dimensioni complessive della costruzione. Gli angoli e i registri bassi ospitavano sempre i blocchi più grandi e più squadrati; i registri alti vedono in posa conci più piccoli e pezzame medio. I perimetrali sull'esterno salivano al terzo medio della 


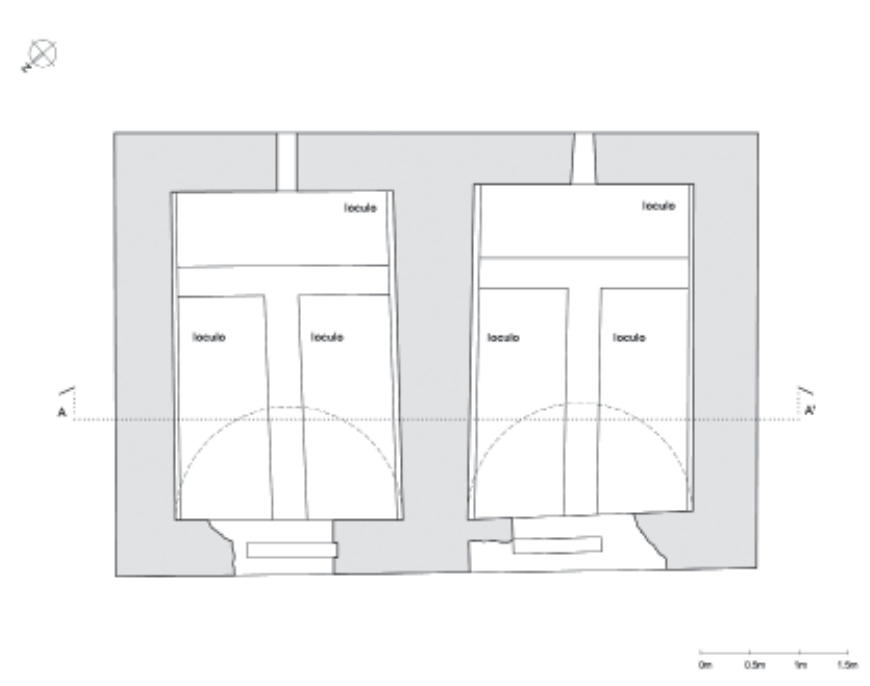

Fig. 15. Ka6, pianta.

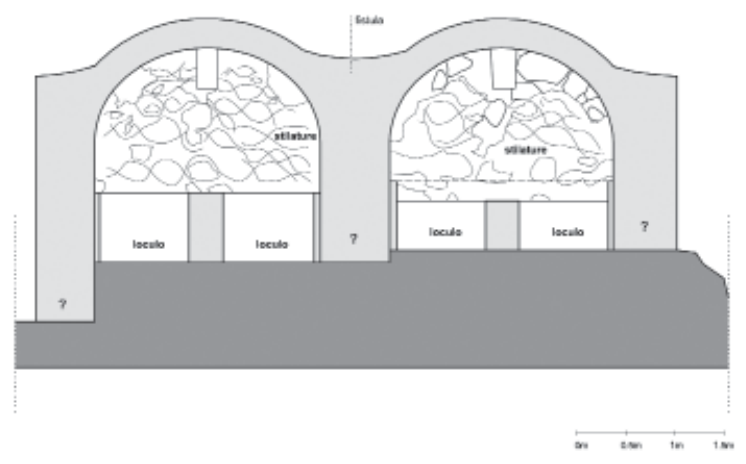

Fig. 16. Ka6, sezione AA'.

volta creando così una spalla per le spinte; la stessa volta era nascosta da due spioventi. Diverso è il caso della presenza della cupola che poggiava su una base quadrangolare o rettangolare. Questa scelta costruttiva per quanto si deduce dalla tecnica messa in opera, creava un problema nel raccordare una base poligonale con una struttura circolare. Si è vista sempre una grande difficoltà affrontata dagli operai nella creazione dei pennacchi al punto di dover ricorrere ad una fascia di muratura intermedia prima dell'imposta della calotta oppure a differenziare le altezze o le forme degli stessi pennacchi che rasentano una foggia di tromba d'angolo ${ }^{23}$.

23 È opportuno richiamare un dato relativo alla capacità tecnica di erigere una cupola. Sembra che altrove (Karkabō [Hellenkemper un Hild 2004, 608]; Alakilise [Hellenkemper un Hild 2004, 609]; Sydima [Hellenkem-

\section{Materiali di costruzione e murature}

La natura rocciosa del terreno e la sua orografia hanno svolto un ruolo importante nel processo costruttivo. Il calcare impera, certamente quello locale. Tagliata perfettamente o meno regolarmente, questa pietra era utilizzata in conci per i grandi paramenti di sostegno, come anche per le volte delle tombe più monumentali (foto 18). Anche le cornici e mensole, semplicemente sagomate, sono di calcare e segnano non solo nelle rombe e nelle chiese, ma anche negli edifici civili l'imposta di una volta o di un arco. Il marmo è quasi del tutto assente - tutto il decoro marmoreo delle chiese era comunque importato ad eccezione del concio di chiave nella $\mathrm{Ka} 2$, accostato a sua volta da un altro concio marmoreo. L'impiego costruttivo del laterizio, pur se in quantità minima, accade solo nella cupola della Ge2, ed è da sottolineare come esso fosse di riuso $^{24}$. A parte v'è la considerazione dell'impiego di frammenti laterizi nella muratura come nella malta idraulica. Una costante tecnica è il ricorso a quanto si possa chiamare lo "pseudo-laterizio" inciso sull' arriccio e dipinto in rosso. Lo si è visto in varie tombe e sempre su superfici curve (cupola, esedre, arcate); in realtà non si tratta di una peculiarità tecnica propria alle tombe, ma è un ritorno usuale in molti

per un Hild 2004, 854] la procedura tecnica sia stata di gran lunga superiore ai nostri casi, pur avendo un diametro da coprire più largo.

24 Sparuto è l'uso del mattone negli altri edifici. Un modulo di tre mattoni in posa radiale si ritiene nell'arco dell'ingresso centrale della Chiesa III; sul fronte dell'arco dell'abside a Kekova, già citata prima in un caso diverso; negli archi dell'impianto termale a Gemile Köyü (inedito); ancora, ma in posa orizzontale per creare il piano d'imposta di due finestre in un edificio civile a Karacaören. Probabilmente vi saranno altri casi di questo genere, ma nulla toglie alla considerazione che il mattone era raro e, se usato, richiama un uso non prettamente locale, ma precedente. 


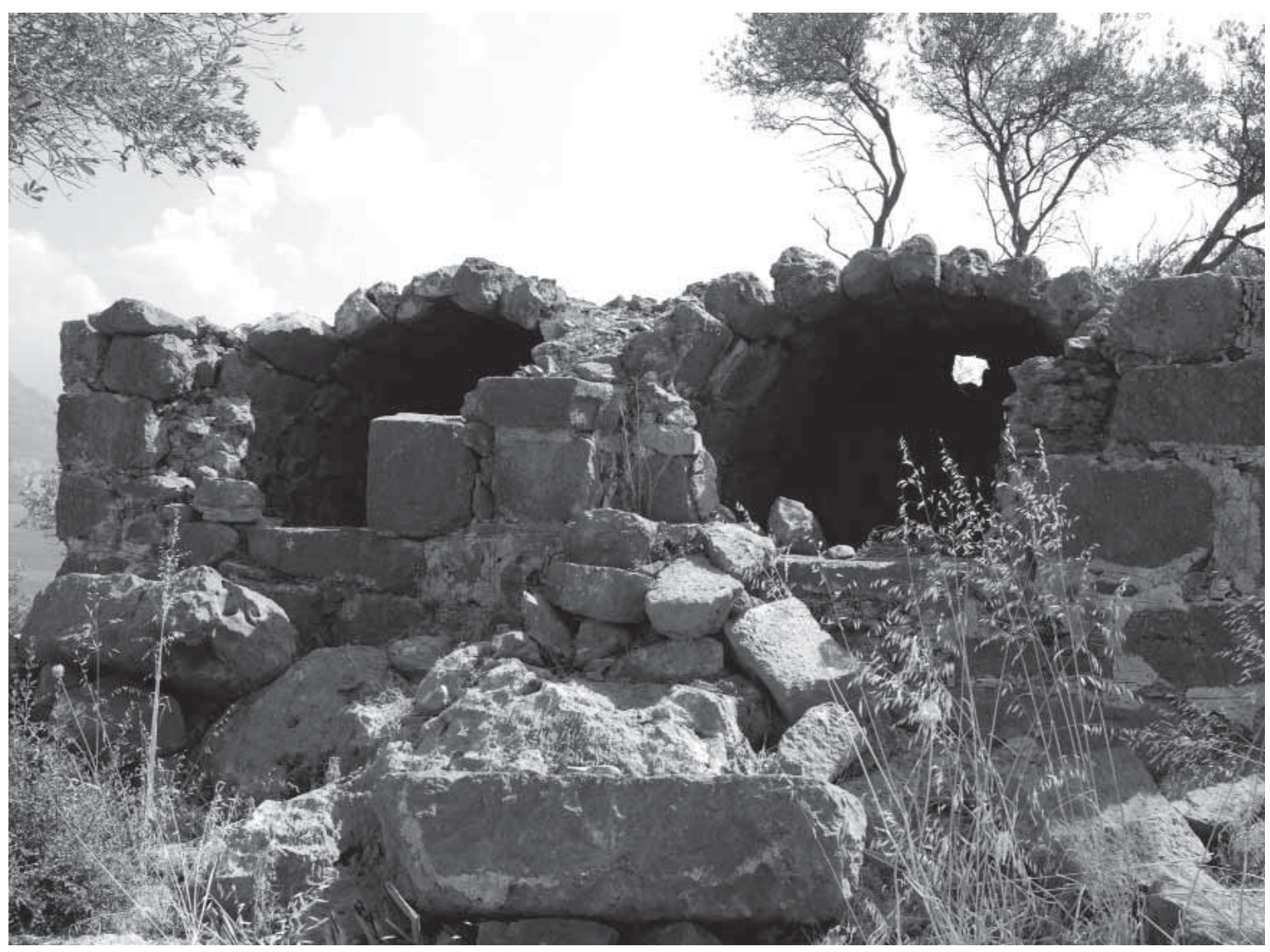

Foto 16. Ka6, tomba a camera doppia. Prospetto sud-ovest.

edifici delle isole, come detto precedentemente, adottato per sottolineare le giunture dei conci.

Le tecniche murarie sono quelle tipicamente bizantine. Questo significa che i facciavista esterni ricorrono al concio più o meno squadrato che può ricoprire tutto il muro o essere impiegato nei registri inferiori. Di solito i paramenti murari esterni hanno i conci rozzamente squadrati con giunti riempiti con piccolo pezzame, frammenti laterizi cementati con abbondante malta (foto 2 e 4). Le volte ricorrono sia ai conci più o meno squadrati, a partire dall'imposta verso il culmine e a scaglie litiche o blocchetti sagomati come mattoni nella posa radiale verso il sommo della cupola. Il facciavista interno dei muri perimetrali ricorre usualmente a blocchi rozzamente squadrati con abbondante malta, oppure a pezzame medio affogato in molta malta ${ }^{25}$ e per la gran parte delle tombe

25 Nei casi delle tombe a sarcofago spesso si notano, dovuti alla forma propria della curvatura dell'ogiva, gli in questione il riempimento interno (il sacco) era costituito da pietre di media grandezza, frammenti laterizi e molta malta. Tutti i tipi di muratura ricorrono al medesimo tipo di malta molto compatta, di colore grigiastro costituita soprattutto da calcare frantumato, lapilli e frammenti laterizi. A proposito dell'assisa muraria, nei muri con blocchi regolari va da se che la posa seguiva un andamento abbastanza regolare, ma nel caso che i blocchi non fossero regolarizzati l'assisa si raggiungeva pel tramite del pezzame all'interno dei giunti. La migliore, forse in assoluto, resta quella posta in opera sulla $\mathrm{Ka} 2$ che facendo ricorso al pezzame di varia grandezza l'assise persegue il suo perfetto andamento orizzontale. Infine, in due casi soltanto (Ka3 e Ka5) si è trattato di un opus quadratum che per gli incastri fra i blocchi sembra richiamare un opus poligonale e in un solo caso (Ge1) esiste un tipo che alla lontana si possa annotare come un opus

interni affidati a pezzame medio e scaglie. 


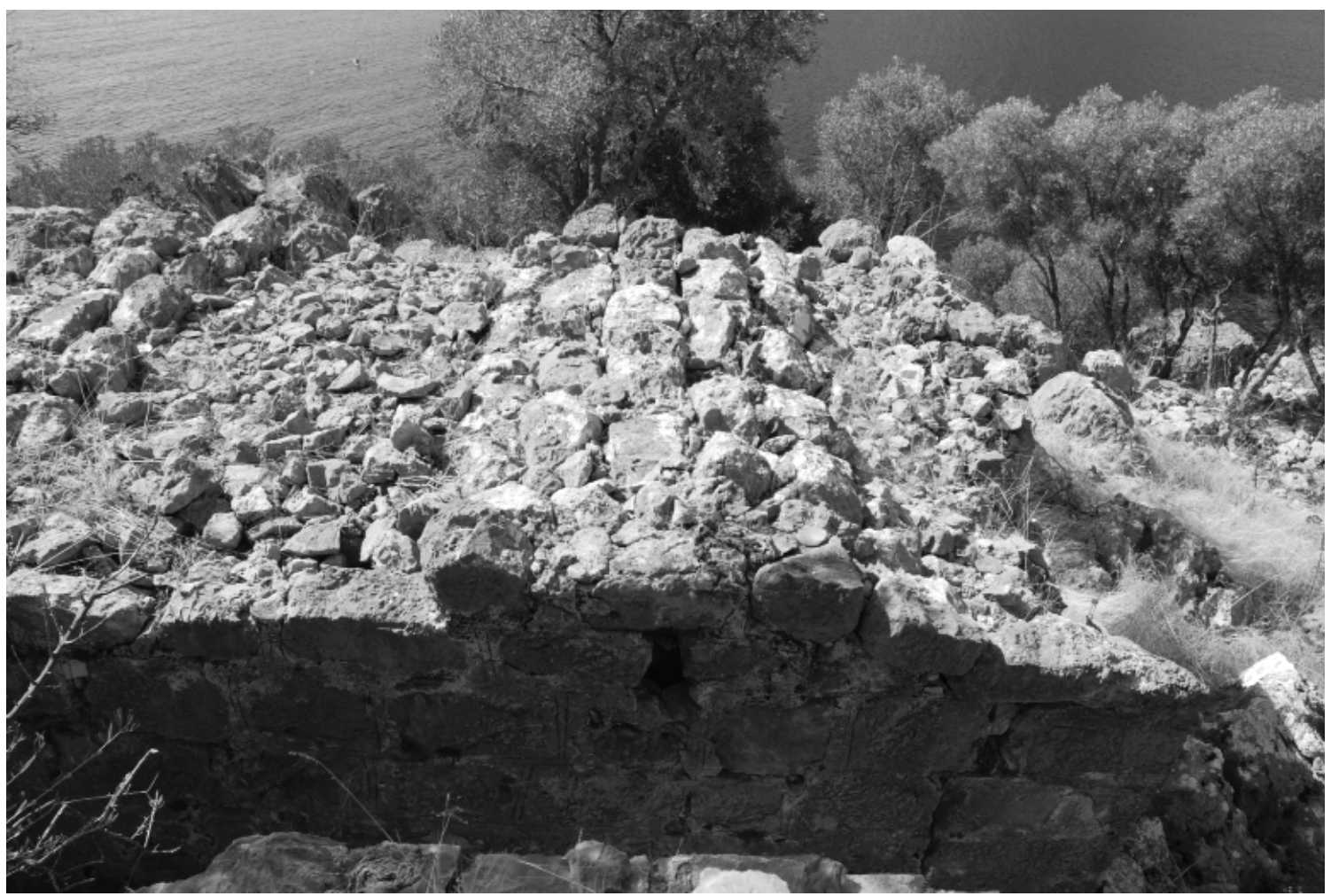

Foto 17. Ka6, tomba a camera doppia. Prospetto est.

mixtum e che consiste in un alternanza di moduli in laterizio e blocchetti calcarei. La maggioranza delle tombe non ha avuto bisogno di fondazioni perché costruita su un banco roccioso. Non di rado il banco di roccia diveniva esso stesso il paramento della tomba.

\section{Stilature, affreschi e rifiniture}

Come era di prassi, l'arriccio posto sui paramenti murari riceveva la sua stilatura. Nel territorio esaminato due sono fondamentalmente i tipi di stilatura rinvenuti: il primo a forma poligonale che in molti casi ma non sempre andava a coincidere con l'andamento dei giunti, il secondo invece assumeva un andamento circolare o sinusoidale che non rifletteva nessun andamento murario sottostante. Vi sono, accanto a queste due, delle leggere varianti che prevedono una stilatura circolare all'interno di una poligonale. In aggiunta v'è l'apparizione di una lisciatura costituita da due li- nee orizzontali segmentate all'interno da incisioni diagonali; in un solo caso quest'ultima trova una variante nella Ka6 con incisioni incrociate all'interno delle linee parallele. Un discorso a parte a proposito di stilature è l'incisione poligonale sui conci in seguito dipinte in rosso (foto 5). A questo si aggiunge anche l'incisione e pitture in rosso, ma solo nel caso di Ge5, su un pezzame sottostante che non è un concio rettangolare ${ }^{26}$. Un ultima osservazione è la copertura degli spioventi, delle cupole e in molti casi dei muri laterali con uno strato di malta idraulica, l'opus signinum.

\section{DATAZIONE}

L'architettura funeraria è un rispettoso riflesso di quella civile ed ecclesiastica. Quest'ultima, assieme alla decorazione marmorea per le chiese (con nota tipologia costantinopolitana) e

26 Sono presenti esempi analoghi nelle sezioni cupolate del corridoio voltato. 


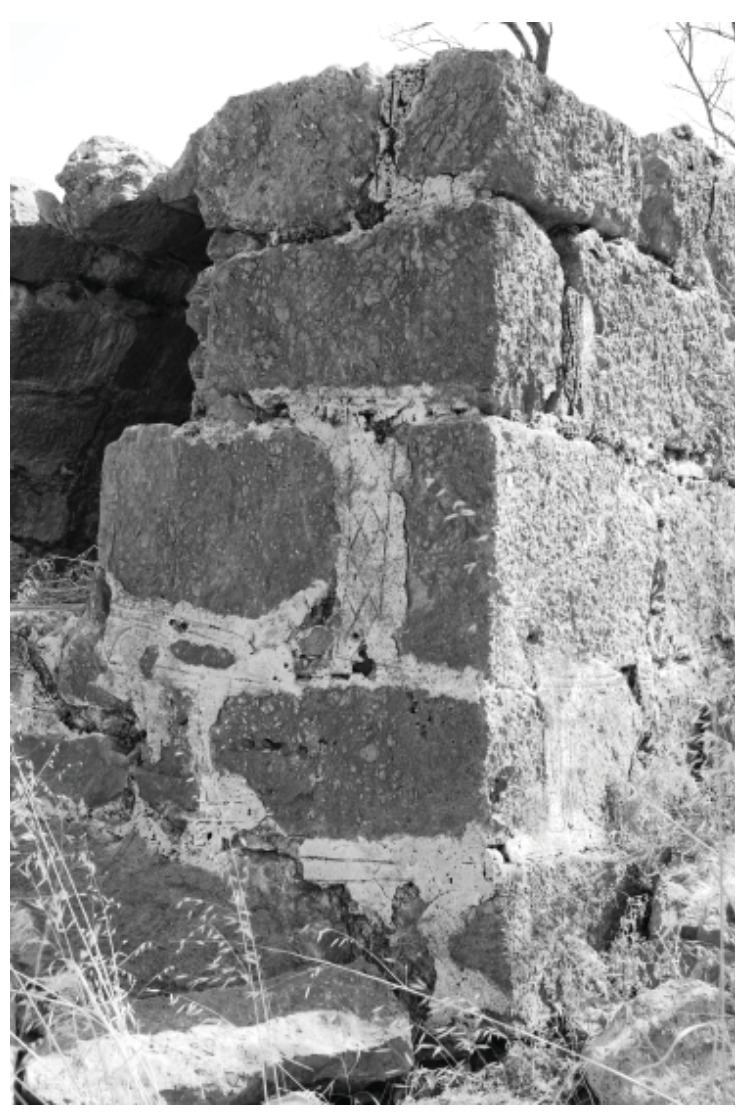

Foto 18. Ka6, tomba a camera doppia. Dettaglio della tecnica muraria.

quanto resta affrescato fa parte del patrimonio bizantino del VI secolo; tale anche le tombe in questione. Si pensa che l'intero arco cronologico di questo secolo sia stato la spanna temporale entro cui le varie aree sepolcrali con i rispettivi monumenti abbiano visto la luce. Certamente v'è da porre un terminus ad quem che l'inizio delle invasioni arabe per mare richiede; qualche rifinitura o, come detto nelle pagine precedenti, qualche mano posteriore può essere accaduta agli inizi del VII secolo, ma qualsiasi tipologia sepolcrale affrontata richiede ancora una situazione urbana non profondamente scossa nelle sue fondamenta sociali ed economiche. All'interno, dunque, di questo tempo è avvenuta anche la sistemazione dell'area sepolcrale presso la Ka1 di Karacaören, come bisogna ritenere della stessa contemporanea organizzazione urbanistica l'intersecarsi del corridoio voltato con qualche tomba ad essa pree-

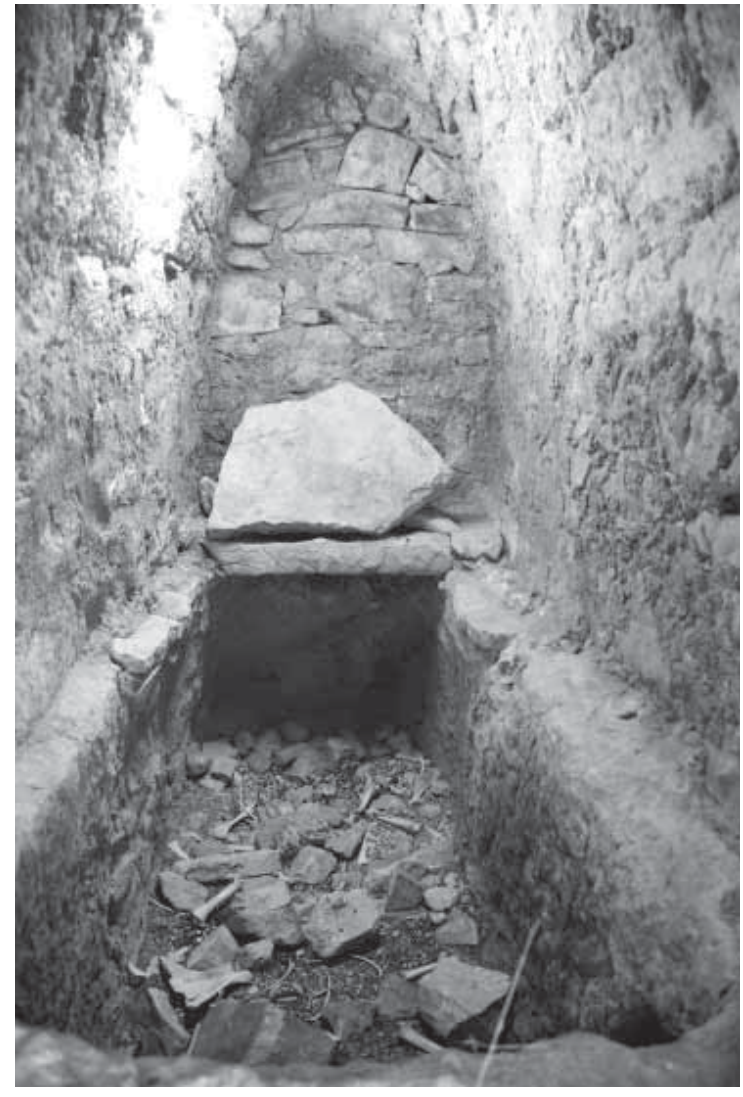

Foto 19. Karacaören, una tomba a sarcofago licio. Interno. Necropoli nord.

sistente. La monumentalità dell'architettura funeraria risponde al generale benessere del centro e probabilmente appartiene alla fase finale di questo orizzonte temporale anche la terza fase della tomba Ge5 di Gemile.

\section{CONCLUSIONE}

Dopo quanto è stato detto, sembra che vi sia una differenza di fondo fra i sepolcreti, li si chiami necropoli, rinvenuti a Gemile e le sepolture sparse, senza un ordito chiaro se non l'insistenza della vicinanza alla chiesa e alla Ka1, presenti a Karacaören. Da una lettura panoramica del sistema d'urbanizzazione della città di Gemile si opta nel credere che vi sia stata una scelta intenzionale da parte delle autorità nel porre le aree sepolcrali 


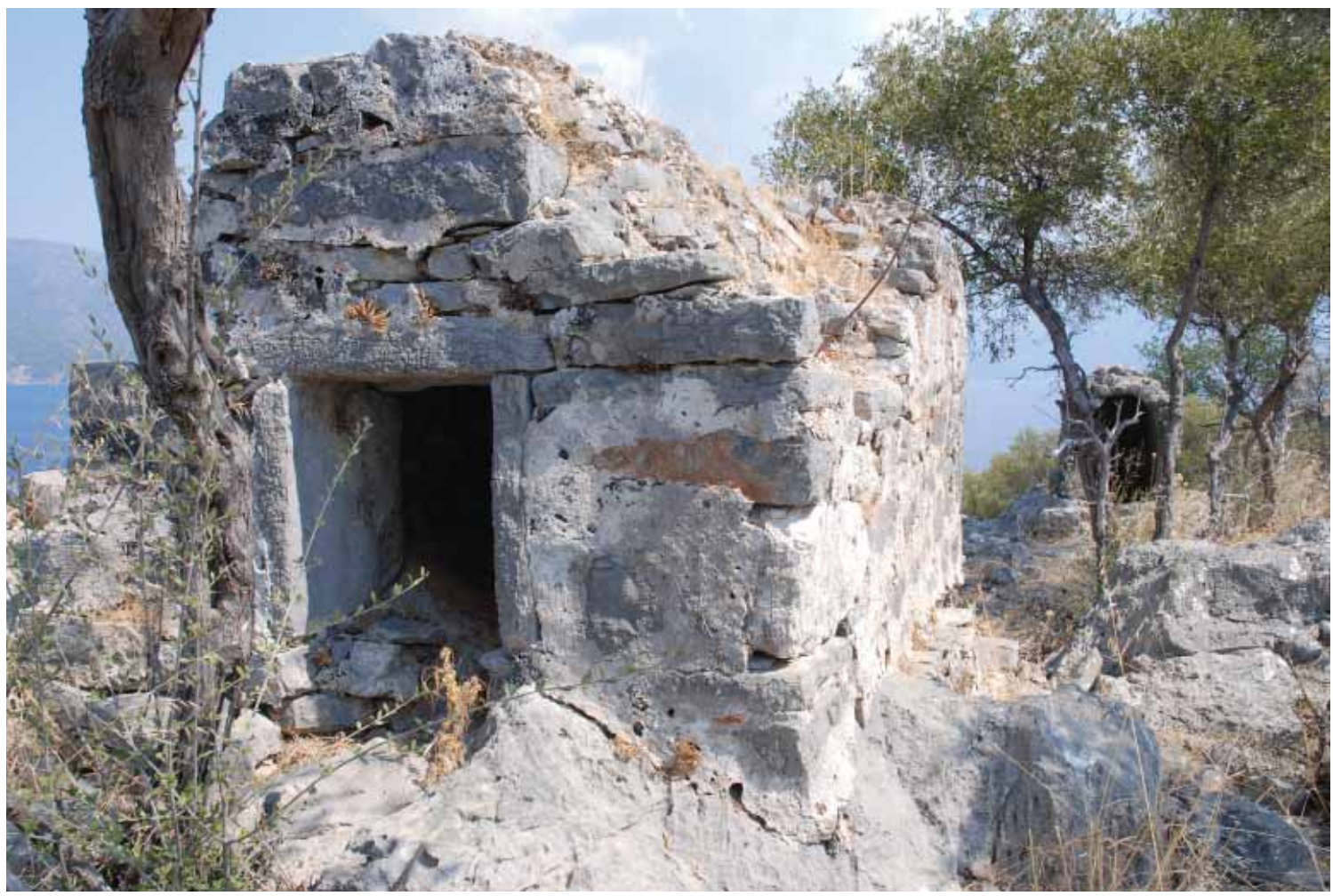

Foto 20. Karacaören, una tomba a camera e una tomba a sarcofago licio. Interno.

Necropoli nord.

in settori non abitativi ${ }^{27}$. Tutto il versante settentrionale dell'isola è densamente abitato; accanto alle abitazioni poste su un considerevole terreno scosceso, presso la battigia si ritrovano le installazioni commerciali e gli approdi importanti da cui partono assi viari a scala verso il culmine della collina, si da incrociare l'asse principale che corre da ovest ad est. Ebbene, questa larga e riparata area è priva di monumenti sepolcrali. Questo modus agendi urbanistico sembra un accettato compromesso, in questa età, fra il divieto di porre il sepolcro in città e una separazione dell'area sepolcrale nella città ${ }^{28}$.

27 Questo è evidente nell'estesa necropoli orientale; se si son letti correttamente i resti murari di qualche altro edificio presente ad est e a sud-est, si tratta di edifici commerciali che si distanziano considerevolmente dai gruppi tombali. Si è dell'opinione che qualora si dovesse pensare a "cimiteri" per i poveri, elemento su cui torneremo, l'estesa area orientale dell'isola di Gemile sarebbe stato il posto più indicato.

28 Un caso analogo si ha ad Alakıșla, in Caria: Ruggieri 2003, 209-213; non vi sono tracce di necropoli all'interno
Detto questo, vi sono ovviamente delle eccezioni da menzionare. Ad est della Chiesa II, lungo la strada principale che s'avvia verso la Chiesa III, vi sono un paio di tombe, ben allestite, parzialmente scavate nella roccia e per poter usufruire della vicinanza alla chiesa si sono avvalse di gradini scavati nella parete rocciosa per impiantare $\mathrm{i}$ loculi e relative coperture con cementizio ${ }^{29}$. Nel prosieguo della strada verso la Chiesa III, si incontrano le due tombe a cupola; la prima all'inizio del terrazzamento a nord della chiesa, mentre la

del plesso urbano fortificato ad Osmaniye, in Caria: Hattersley-Smith and Ruggieri 1990, 135-164; cf anche Claude 1969, 97-98. Da un punto di vista urbanistico il problema si pone differentemente quando si tratta di una città classica divenuta cristiana durante i secoli; in questo caso i cristiani hanno riutilizzato la necropoli già esistente. 29 A Gemile, come molto più comunemente a Karacaören, si potrebbe pensare al costume sepolcrale ad sanctos, avessimo delle tracce di deposizioni particolari. La carenza di identificabili deposizioni (a parte la probabile dedicazione della Chiesa II a S. Nicola dovuta alle due iscrizioni degli stipiti della porta nord), ci esime dal fare qualsiasi ipotesi a riguardo. 


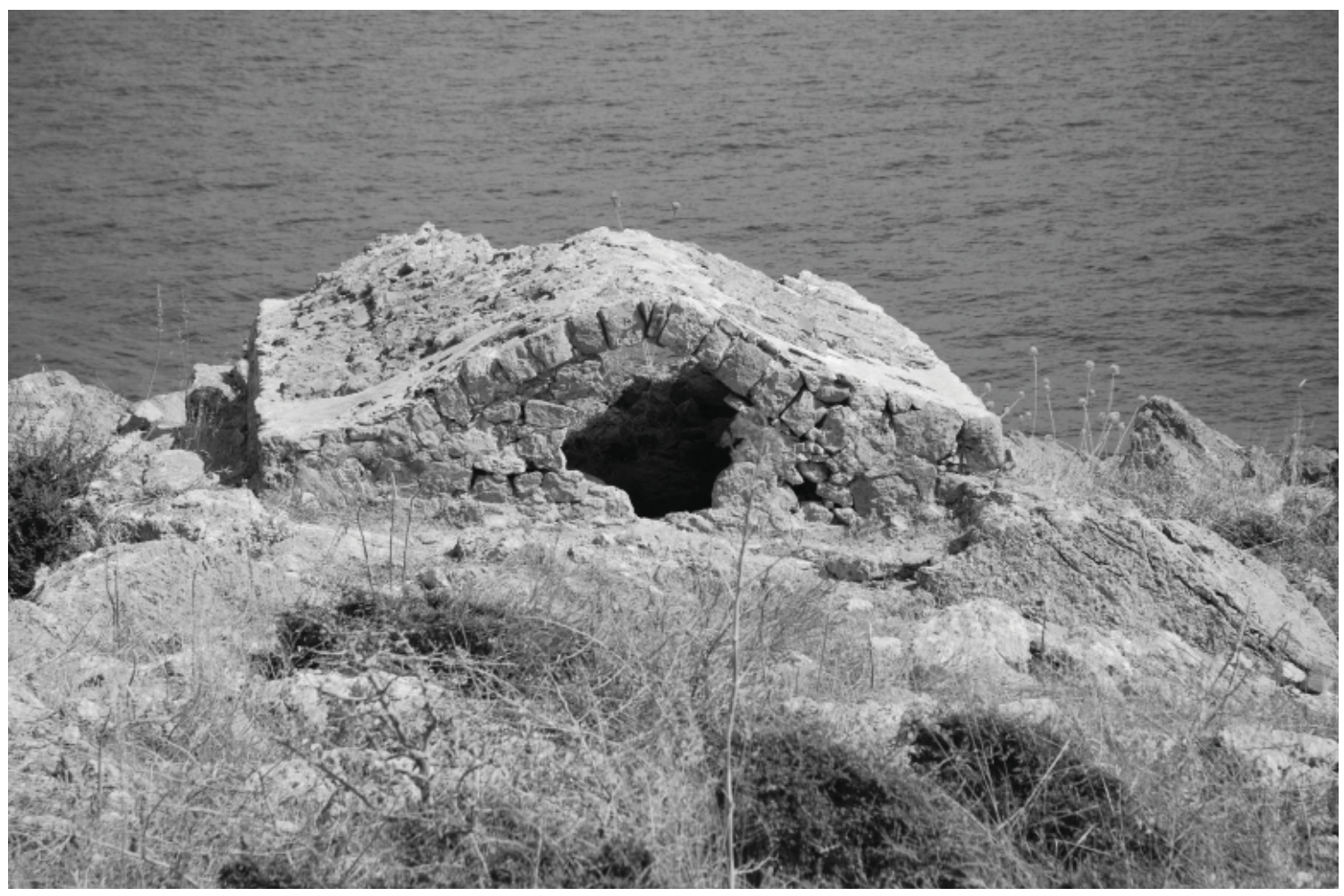

Foto 21. Karacaören, una tomba a camera. Area est dell'isola.

seconda sotto il terrazzamento, nei pressi dell'ingresso nord al corridoio voltato. Vien da porre una domanda: sono queste sparute tombe interventi privati avvenuti dopo la decisione di approntare determinate aree urbane per la sepoltura? Al momento non si può dare una risposta certa a causa della carenza di corredo e di una stabilita cronologia per le aree sepolcrali ${ }^{30}$.

Se non si va errato, all'interno del corpo epigrafico pubblicato da T. Masusa, una sola iscri-

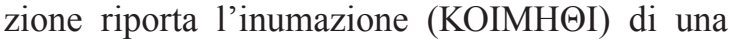
persona il cui nome è scomparso. Questa epigrafe è stata incisa sull'arriccio interno della volta di una tomba parzialmente scavata nella roccia dietro la Chiesa II ${ }^{31}$. Questa modalità epigrafica, l'es-

30 In due casi solamente si è rinvenuto uno scarto cronologico (leggero o considerevole) d'un certo interesse. Una tomba a camera presso il corridoio voltato interferisce con il passaggio voltato del corridoio: in realtà si pensa che la tomba sia preesistente al disegno del corridoio. L'altro caso è dato dalla tomba Ge 5 che mostra interventi murari differenti.

31 Masuda 2010, 244; un'altra iscrizione incisa sulla roccia sere cioè incisa sull'arriccio interno, spiega per un verso la mancanza di iscrizioni propriamente incise su lastre di chiusura e conferma, per un altro verso, l'ipotesi che le iscrizioni, se v'erano, erano dipinte o graffite sul registro sovrastante l'arco cieco della facciata o lungo gli stipiti laterali dello stesso, una caratteristica rinvenuta in vari esempi su ambo le isole ${ }^{32}$.

La mancanza di informazioni che usualmente l'epigrafia funeraria offre, rende in questi casi silente la varietà dei monumenti e la posizione sociale dei lori proprietari. Le tombe contengono da uno a tre letti funerari, molto diffusa è la fossa scavata nella roccia con semplice copertura a lastra piatta (chamosorion) ${ }^{33}$. Naturalmente

a Karacaören ha sentore di funerario: Masuda 1995, 124125 (Masuda riempie la lacuna con ódòv riferendosi alla strada nella roccia). La natura sepolcrale dell'iscrizione è data da "عiç àvó $\pi \alpha v \sigma ı v "$, benché sfortunatamente non si ha un riferimento immediato sull'opera fatta costruire.

32 Come detto, Ka3 portava un'iscrizione sul lato nord, su una superficie calcarea praticamente corrosa.

33 Più propriamente per un letto si avrebbe un $\mu$ ovó $\sigma \omega \mu \mathrm{ov}$ 
quest'ultimo tipo di sepoltura si ritrova su ambo le isole in qualsiasi area funeraria senza mostrare nessun particolare segno di ornamentazione architettonica. Vien da pensare, pur se ipoteticamente, che questo fosse il tipo di tomba per la classe povera (su ambo le isole non s'è rinvenuta struttura alcuna che potesse far pensare ad una tomba collettiva), pur se non sempre, e che la classe agiata, abbastanza diffusa su quest'isola votata al commercio, patrocinava lasciando però alla chiesa il dovere dell'inumazione gratuita ${ }^{34}$. Se la ricchezza di Gemile lascia pensare con buon ragione all'antico costume del mecenatismo locale ${ }^{35}$ nell'approntare delle fosse, spettava tuttavia alla chiesa il compito gratuito del'inumazione ${ }^{36}$.

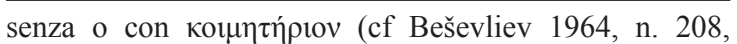
143-144; Robert 1965, n. 1), mentre a due letti avrem-

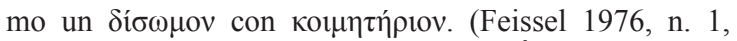
p. 269-271 da Salonicco; Robert, ib.). È degno di nota

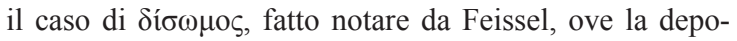
sizione dei corpi è avvenuta in due diverse date accertate dall'iscrizione. Un pluteo cristiano chiudeva una tomba che racchiudeva due deposizioni; queste erano divise in

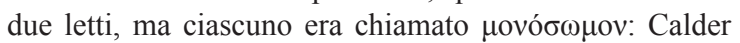
1956, n. 89, p. 17 e Pl. 6. In genere su questo soggetto, cf. Koukoules 1951, 198-203.

34 Rebillard 1999, 278-282.

35 È fuori dubbio che le due isole e i propinqui siti sulla terraferma testimoniano una considerevole agiatezza economica. Ad Ölüdeniz, dove le chiese sono state archeologicamente scavate (ciò che non è accaduto sulle nostre due isole, se non per un terzo della Chiesa III), tutte avevano il pavimento mosaicato. Dove questo s'è conservato, si vede la testimonianza epigrafica di un gruppo di persone ( $\tau$ oĩ $\sigma v v \delta o ́ \tau o t \varsigma)$, di singoli, di donne proprietarie d'una nave. Inoltre, un architrave marmoreo, pagato probabilmente da un certo Teodosio, medico, ricorda il riposo eterno del vescovo Paolo: cf. Malkoç-Tsuji 2005, 7-9). L'area scavata nella Chiesa III a Gemile ha consegnato la grande iscrizione di Makedôn, un orefice, che ha pavimentato con mosaico la navata centrale della chiesa: Asano 2002, 234; Masuda 1995, 241-243. Un particolare mecenatismo inoltre è attestato dall'intervento sull'accesso e viabilità sull'isola di Karacaören. Grandi iscrizioni sulle pareti di roccia tagliata per creare percorsi ricordano Stefano, Nilos Zoilos ed uno sconosciuto. All'interno dunque di questo diffuso costume, nessuna epigrafe testimonia un similare intervento sull'architettura funeraria.

36 Inizialmente v'è una legge di Anastasio che concede un reddito di 70 libbre d'oro alla Grande Chiesa di Costantinopoli perché i funerali fossero gratuiti per i poveri della capitale: Cod. Iust. I,2,18. Il VI sec., comunque, vide la crisi dei kopiatai (dekanoi o lektikarioi), gli incaricati per
La varietà delle forme architettoniche sparse più a Karacaören che a Gemile lascia sorpresi. Se la tomba a camera ha illustri e più rifiniti esempi nell'architettura del periodo classico, si ritrova anche il ricorso intenzionale al profilo del sarcofago licio operato con semplice muratura. Inusitata è la tomba con esedre esterne alzate con conci ben tagliati nel contenere un singola fossa all'interno: la sua rifinitura architettonica e l'ottima esecuzione tecnica del ciclo pittorico interno fanno pensare a qualche defunto di riguardo. Se in tutte queste forme v'è un voluto richiamo alle soluzioni assodate nei secoli precedenti, è da ritenersi originale la soluzione architettonica a cupola, in sé molto particolare ${ }^{37}$.

Fra le varie caratteristiche architettoniche sepolcrali presentate nelle pagine precedenti è probabile che due possono avere un loro significato all'interno del rituale di sepoltura. La presenza di chiese nelle immediate vicinanze lascia pensare allo svolgimento processionale della salma verso il taphos, più agevolato a Gemile, più irto e complesso a Karacaören ${ }^{38}$. Ciò che i testi liturgici stanno a riferire come $\dot{\varepsilon} v \tau \alpha \dot{\alpha} \varphi \omega$ probabilmente abbia avuto luogo negli spazi antistanti alle tombe. Alcune di queste hanno conservato a terra una ristretta area delimitata da una forma semicircolare

i funerali; per essi Giustiniano emette due Novellae (43 e 59): cf l'analisi fattane da Rebillard 1999; 274-275; Demicheli 1990, 72-75. La stele di Tanagra (fine IV-inizi V sec.) richiama: "Ai poveri inoltre si dia subito ciò che basta attingendolo dalla sostanza che si ha ...": Guarducci 1978, 339 (qui si parla anche del conforto del lume durante la notte).

$37 \mathrm{La}$ cupola sulla tomba di S. Ticone provocava sorpresa per la sua bellezza: Usener 1907, 2828-29, 139. Una strana forma ottagonale aveva la tomba di Atenogene: Maraval 1990, 4313.

38 Maisano 1982, cc. 77-78, 112-116 illustra la processione verso il sepolcro (la salma, durante la processione, non era coperta). Le fonti sono numerose a proposito di santi e sante; ben conosciuti sono i funerali di S. Basilio, di Macrina e Cesario in Cappadocia, dove il rito è pennellato dai Padri Cappadoci in prosa elegante. In genere i punti salienti del rito sono rinvenibili nel testo dello PsuedoDionigi Areopagita, La gerarchia ecclesiastica, ed. da S. Lilla, Roma 2002, 142-155 e riproposti dalla tradizione eucologica (De Meester 1930, 77 e ss.; Arranz 1997, 99-117). 
in muratura oppure un accesso privato o scale di accesso alla tomba ${ }^{39}$. Sempre in facciata si riscontra la seconda particolarità: mensole aggettanti o mensole-sedili posti su ambo i lati della facciata $\mathrm{o}$ ancora lungo la facciata nel registro più basso. Forse è quest'ultimo dispositivo architettonico che, pur se nella sua semplicità, allaccia la prassi sepolcrale ai secoli precedenti. Si pensa alle mensole per i lumi, come ai sedili per la permanenza dei familiari nei giorni anniversari con il relativo consumo dei kollyba.

L'architettura sepolcrale delle isole ben riflette lo status agiato della popolazione la cui cultura era ancora parzialmente legata a forme passate di vita sociale ed urbana. Le differenziate forme di questa architettura sono uno specchio, almeno in buona parte, di modelli antichi, altre rappresentano una novità che architettonicamente non si presentano aggraziate e ben risolte. È da pensare che la richiesta di avere una cupola fosse un tentativo di rappresentare la forma tardoantica del mausoleo? Resta unica la tomba ad esedre che ad una pianta innovativa dall'esterno risolve la soluzione del volume interno affidandosi alla consueta volta a botte. La tecnica, bisogna dirlo, anche lì ove non sia stata raggiunta un'armonica soluzione architettonica, si mantiene su un buon livello toccando anche tratti di grande maestria. V'è una finale considerazione di carattere più generale. Si è documentato in molti casi i momenti figurativi, pur se frammentari, che ornavano soprattutto la facciata arcuata d'ingresso e l'interno. D'altro canto si è constatato la carenza epigrafica che accompagna questa architettura funeraria cristiana. Se i bizantini di questa geografia hanno volto lo sguardo alle forme architettoniche antiche, non hanno però optato ad incidere il marmo o il calcare per conservare a perenne memoria il nome del defunto; essi si sono piuttosto affidati alla simbologia e questa sempre affrescata. Ove

$39 \mathrm{Si}$ potrebbe pensare all'antica prassi legale di proprietà relativa all'area della tomba e dell'area ad essa attinente; non si hanno in questi siti nessun accenno a proposito. si trova un accenno di scrittura, questa si affida al pennello d'un pittore e non allo scalpello d'un incisore epigrafico. La mancanza, dunque, di uno scritto inciso esposto costituisce una caratteristica essenziale e molto sintomatica di questa originale architettura sepolcrale bizantina.

\section{BIBLIOGRAFIA}

\section{Arranz 1997}

M. Arranz, 'La preghiera per i defunti nella tradizione bizantina, II-6', OCP 63, 1997, 99-117.

\section{Asano 2002}

K. Asano (ed. by), Higashichichukai no Kouwantoshiiseki no Sougouteki Kenkyu (= Comprehensive Study of the Harbour City Site in East Mediterrenean), Aichi University 2002.

\section{Asano 2010}

K. Asano (ed. by), The Island of St. Nicholas. Excavation and Survey of the Gemiler Island Area, Lycia, Turkey, Osaka 2010.

\section{Beševliev 1964}

V. Beševliev, Spätgriechische und lateinische Inschriften aus Bulgarien, Berlin 1964.

\section{Calder 1956}

W.M. Calder, Monuments from Eastern Phrygia, (Monumenta Asiae Minoris Antiqua VII), Manchester 1956.

\section{Claude 1969}

D. Claude, Die byzantinische Stadt im 6. Jahrhundert, München 1969.

\section{Çevik 2006}

N. Çevik, 'The social structure as reflected through the necropolis of Trebenna', in K. Dörtlük et Alii (ed. by), The III Symposium on Lycia, Proceedings, Antalya 2006, I, 177-178. 


\section{De Meester 1930}

P. De Meester, Studi di Rito bizantino. Libro II, Parte VI. Rituale-Benedizionale bizantino, Roma 1930.

\section{Demicheli 1990}

A.M. Demicheli, La МЕГА $\Lambda$ EKК $\Lambda$ H $\Sigma$ IA nel lessico e nel diritto di Giustiniano, Milano 1990, $72-75$.

\section{Equini Schneider 2003}

E. Equini Schneider, 'I chamosoria', in E. Equini Schneider (a cura di), Elaiusa Sebaste II. Un porto tra Oriente ed Occidente, Roma 2003, 454-457.

\section{Feissel 1976}

D. Feissel, 'Notes d'épigraphie chrétienne', BCH 100, 1976, 269-281.

\section{Filipović 2012a}

A. Filipović, 'L'architettura sepolcrale bizantina sulle isole di Gemile e Karacaören in Licia', parte I, OCP, 78/1, 2012, 149-177.

\section{Filipović 2012b}

A. Filipović, 'L'architettura sepolcrale bizantina sulle isole di Gemile e Karacaören in Licia', parte II, OCP, 78/2, 2012, 439-466.

\section{Foss 1994}

C. Foss, 'The Lycian Coasts in the Byzantine Age', DOP 48, 1994, 1-52.

\section{Guarducci 1978}

M. Guarducci, Epigrafia greca. IV. Epigrafi sacre pagane e cristiane, Roma 1978.

\section{Krueger 1900}

P. Krueger (ed.), Corpus Iuris Civilis, Berolini 1900.

\section{Hattersley-Smith and Ruggieri 1990}

K. Hattersley-Smith and V. Ruggieri, 'A Byzan- tine City near Osmaniye (Dalaman) in Turkey. A Preliminary Report', OCP 56, 1990, 135-164.

\section{Hellenkemper und Hild 2004}

H. Hellenkemper und F. Hild, Lykien und Pamphylien, Tabula Imperii Byzantini B. 8, Wien 2004.

\section{Koukoules 1951}

$\mathrm{Ph}$. Koukoules, Vie et civilisation byzantine, IV, Atènes 1951, 198-203.

\section{Malkoç and Tsuji 2005}

I. Malkoç and Sh Tsuji, 'Preliminary Report on the Excavations in Ölüdeniz Area, Lycia, by Fethiye Museum, Ministry of Culture, Turkey, during 1999-2004', Al-Rāfidān 26, 2005, 1-24.

\section{Maraval 1990}

P. Maraval, 'La Passion inédite de S. Athénogène de Pédachthoé en Cappadoce', Subsidia Hagiographica 75, 1990, 20-85.

\section{Masuda 1995}

Masuda, "Greek Inscriptions in the Ölüdeniz-Gemiler Ada Bay Area", in Sh. Tsuji (ed. by), The Survey of Early Byzantine Sites in Ölüdeniz Area (Lycia, Turkey). The First Preliminary Report, (Memoirs of the Faculty of Letters Osaka University, 35), Osaka 1995, 124-125.

\section{Masuda 2010}

T. Masuda, 'Inscriptions', in K. Asano (ed. by), The Island of St. Nicholas. Excavation and Survey of the Gemiler Island Area, Lycia, Turkey, Osaka 2010, 237-252.

\section{Maisano 1982}

R. Maisano (ed. da), G. Mosco, Il Prato, Napoli 1982.

\section{Lilla 2002}

S. Lilla (ed. da), Psuedo-Dionigi Areopagita, La gerarchia ecclesiastica, Roma 2002. 


\section{Rebillard 1999}

È. Rebillard, 'Les formes de l'assistance funéraire dans l'empire romain et leur évolution dans l'Antiquité tardive', Antiquité Tardive 7, 1999, 278-282.

\section{Robert 1965}

L. Robert, Bulletin Epigraphique, Paris 1965.

\section{Ruggieri 1991}

V. Ruggieri, 'Due complessi termali nel golfo di Macris (Fethiye)', OCP 57, 1991, 179-198.

\section{Ruggieri 1993}

V. Ruggieri, 'Katêchoumenon: uno spazio sociale', in E. Carr, S. Parenti, A. Thiermeyer, R. F. Taft (a cura di), EÕLOGHMA. Studies in Honor of Robert Taft S.J., Roma 1993, 389-402.

\section{Ruggieri 1998}

V. Ruggieri, 'LEBISSOS, MAKRH, MARKIANH e S. Nicola: nota di topografia licia', Byzantion 67, 1998, 140-147.

\section{Ruggieri 1999}

V. Ruggieri, 'Il sito bizantino a Karacaburun e i "Sette Capi” (Licia). Rapporto preliminare', OCP 65, 1999, 298-305.

\section{Ruggieri - Zaffanella 2000}

V. Ruggieri - G.C. Zaffanella, 'La valle degli eremiti nel canyon del Koça Çay a Kızılbel in Licia', OCP 66, 2000, 79-82.

\section{Ruggieri 2003}

V. Ruggieri, Il golfo di Keramos dal tardo-antico al medioevo bizantino, Soveria Mannelli 2003.

\section{Ruggieri e Turillo 2007}

V. Ruggieri e M. Turillo, 'Considerazioni aggiuntive su siti dell'Asia Minore (Caria e Licia [TIB 8]): note storiche, lettura di strutture murarie ed analisi delle tecniche pittoriche', OCP 73, 2007, 123-130.

\section{Ruggieri 2009}

V. Ruggieri, 'La scultura bizantina a Kayaköyü (Licia)', Studi sull'Oriente Cristiano 13/2 (2009) 81-108.

\section{Ruggieri 2012}

V. Ruggieri, "Levissos (?): un caso di topografia urbana in Licia", in Vie per Bisanzio, Atti del XX Congresso Nazionale di Studi Bizantini, a cura di A. Rigo e A. Babuin, Venezia 2012, 883-902.

\section{Tsuji 1995}

Sh. Tsuji (ed. by), The Survey of Early Byzantine Sites in Ölüdeniz Area (Lycia, Turkey). The First Preliminary Report, (Memoirs of the Faculty of Letters Osaka University, 35), Osaka 1995.

\section{Tsuji 1996}

Sh. Tsuji, General Description of Archaeological Sites Recently Surveyed near Ölüdeniz (Fethiye, Muğla), in Essays on Ancient Anatolia and Syria in the Second and Third Millenium B.C., ed. by H.I.H. Prince Takahito Mikasa, Wiesbaden 1996, 259-295.

\section{Tsuji 2001}

Sh. Tsuji, 'Notes from the Field in Ölüdeniz, Muĝla, T.C.', Otemae Journal of Humanities (Otemae Univ., Nishinomiya, Japan, 2001) II, 3-26.

\section{Usener 1907}

H. Usener, Der heilige Tychon, Leipzig-Berlin 1907. 


\section{ONE BYZANTINE NECROPOLIS IN THE GOLF OF BELCEĞIZ: SOUTH LYCIA}

KEY WORDS: NECROPOLIS, TOMB, CHAMOSORION, DOME, VAULT, MASONRY, LIMESTONE, BRICK, OPUS SIGNINUM, GROUTING.

In the golf called Belceğiz (South Turkey) are located several archaeological localities diffused on two islands and the nearby coasts, which can be considered as unique urban complex, and dated to the first half of the sixth century. Considering that the vast necropolis that make up the whole are only on two islands, and along the coasts the tombs are few and isolated, this paper will focus only on the necropolises. On the larger island, Gemile, which is also the so-called urban center (the most intense and most complex settlement), necropolis located in more isolated area of residential areas, with a few isolated graves, however, integrated into the urban fabric: the first necropolis of along the road between the Church and the Church II, the second necropolis is widespread south of the vaulted hall (a specific type of street) third, called the Eastern Necropolis, near the Church of the IV, outside but close to a residential neighborhood, which is also the richest part of the island. Second, the smaller island, Karacaören, has a very different situation and is probably in the local place of pilgrimage. On it there is only one basilica (with the baptistery) surrounded by graves. The following is the analysis of the architecture of several tombs selected for specific and typical architecture: Domed tomb 1 (Ge1), Domed tomb 2 (Ge2), Cruciform tomb (Ge3), Tomb with exedras (Ka1), Tomb with one room (Ka2), Pseudo-Hellenistic tomb 1 (Ka3), Pseudo-Lycian sarcophagus (Ka4), Pseudo-Hellenistic tomb 2 (Ka5), Tomb with two rooms (Ka6). The contribution will be concluded with the final architectural considerations, design techniques, methods of construction and materials, plaster fresco, frescoes and finishing, dating and conclusion. 